ENCUESTA 



\title{
ENCUESTA SOBRE LA INDEPENDENCIA DE LOS MEDIOS DE COMUNICACIÓN SOCIAL
}

\author{
PRESENTACIÓN
}

Nuestra revista con la encuesta del presente número quiere llamar humildemente la atención de nuestros lectores acerca de la complejización que en los últimos tiempos parece aquejar a las libertades de expresión e información, que son básicas en la configuración de una convivencia democrática de calidad. Sabido es que estuvieron ya enraizadas en la Declaración de Derechos del Hombre y del Ciudadano de la Francia de 1789, cuyo artículo 16 disponía: «La libre comunicación de los pensamientos y de las opiniones es uno de los derechos más preciados del hombre; todo ciudadano puede, por tanto, hablar, escribir e imprimir libremente, salvo la responsabilidad que el abuso de esta libertad produzca en los casos determinados por la Ley».

Todos tenemos presente que en sus diversos apartados, el artículo 20 de nuestra Constitución de 1978 protege tanto el derecho «a expresar y difundir libremente los pensamientos, ideas y opiniones mediante la palabra, el escrito o cualquier otro medio de reproducción», que es una libertad ideológica, que tiene tácitamente también por objeto la expresión y difusión de creencias y juicios de valor, como, de otro lado, el derecho a comunicar y a recibir «libremente información veraz por cualquier medio de difusión». Y las libertades anteriores, conforme a la doctrina tradicional, comprenden el derecho a la creación del medio informativo a través del cual la difusión de ideas y la información sobre hechos se hace posible, sin que ello impida la creación de otros medios similares.

Ciertamente el papel de los medios de comunicación en una democracia avanzada, en la terminología del buen preámbulo de nuestra Constitución vigente, de nuestro tiempo es de gran trascendencia y de no desconocible complejidad. El medio recolecta información, no siempre la difunde toda o por entero, y emite a la par opiniones sobre la información, de modo que con frecuencia no es fácil para el lector separar la expresión de pensamientos, ideas y opiniones de la estricta comunicación informativa, pues aquella a menudo se apoya en la narración de hechos y, a su vez, la comunicación de noticias suele estar acompañada de elementos valorativos. Ello obliga a los tribunales a aplicar la doctrina sobre cada derecho según el factor que resulte preponderante en el caso controvertido y, a la par, nos conduce con realismo a recordar la doctrina clásica sobre los medios como formadores de opinión, que 
actúan a diario sobre los lectores u oyentes que buscan producir macizos de opinión, de modo que las ideas del medio adquieren fuerza pública y aún política. Por lo que quizás haya que reconocer con realismo que nuestro sistema garantiza hoy mejor la libertad de expresión y el derecho a informar, que el derecho de todos a estar verazmente informados, que en teoría resuelven la pluralidad de medios y, en última instancia, la acción de los medios de titularidad pública.

Pero el papel real de los medios de opinión pública — televisivos, radiofónicos, agencias de noticias... - no siempre es ejemplar y a menudo es objeto de la crítica sistemática de los partidos ubicados temporalmente en la oposición, sin perjuicio de que cuando alcanzan el poder puedan verse afectados por la misma tentación de manipular la opinión pública. En la teoría más clásica los medios privados pueden estar escorados conforme a los legítimos intereses y los prejuicios, en el sentido más literal del término, de naturaleza ideológica, pues su pluralidad conlleva que otros medios privados estarán diariamente presentes arrojando otra luz con efecto compensador y siendo a la postre los ciudadanos perceptores de la pluralidad de opiniones contrapuestas y de informaciones varias los que en última instancia configurarán la opinión pública preponderante en cada momento. Ahora bien, cuando una aguda crisis económica, como la que viene sufriendo en los últimos años nuestra sociedad, conlleva reducción en las ventas y en la publicidad que sustentan a los diversos medios de comunicación y los mismos se sumergen en resultados económicos negativos, es posible preguntarse hasta qué grado se encuentran en dependencia prácticamente total de sus acreedores, de quienes les conceden interesadamente créditos o de quienes les insertan publicidad pública o privada, también más o menos interesada.

Nuestra revista, fiel a su tradición de plantear en esta ya clásica encuesta introductoria a cada uno de sus números, lejos de ofrecer sus respuestas a los problemas de teoría jurídico constitucional que suscita la dura realidad, se limita como siempre a formular interrogantes a algunos de nuestros más prestigiosos docentes. Ciertamente sobre la problemática que en la práctica presenta esta materia, los constitucionalistas españoles, cuya fecundidad doctrinal está fuera de duda, probablemente por estar en los últimos tiempos muy atentos a otras cuestiones que demandan prioritariamente su atención, no han dedicado atención prioritaria a las inquietudes que emergen en la presente encuesta, sobre cuestiones planteadas desde el mero rigor académico, pero que se pueden considerar como de naturaleza espinosa. Resaltamos lo anterior para que los amigos lectores puedan valorar aún más, si cabe, el esfuerzo profesoral de quienes nos han honrado con sus respuestas, que sin duda interesarán vivamente a nuestros colegas.

\section{CUESTIONES}

1. En qué medida cree importante que la sociedad democrática avanzada que la C.E. desea establecer ha de lograr un sistema político representativo atento a una opinión públi- 
ca libre? $Y$ ¿qué nos quiere decir sobre el papel que juegan y/o deberian jugar los medios de comunicación públicos y privados en la difusión de información veraz y en la acogida de opiniones para la formación de una opinión pública libre?

2. ¿Cabe temer que entre todos los obstáculos para que los medios cumplan bien sus funciones pueden existir interferencias o presiones a los mismos provenientes de los poderes públicos o de los partidos politicos? Si su respuesta es afirmativa: ¿puede sugerirnos tratamientos de Derecho Público para tal problema, basados en modelos foráneos o de propio cuño?

3. Desde nuestra realidad autonómica, ¿qué valoración le merece tanto la actual distribución de competencias en materia de medios, como el ejercicio que se ha hecho de las mismas?

4. ¿Entiende que lo dispuesto en el art. 20.3 CE acerca de que la ley regulará la organización y el control parlamentario de los medios de comunicación social públicos y garantizará el acceso a los mismos de los grupos significativos, respetando el pluralismo y las diversas lenguas tiene en nuestra realidad un nivel de cumplimiento adecuado? ¿Sugeriria $V d$. que tal precepto constitucional disfrutase de un desarrollo legislativo diferente?

5. Más en concreto ¿desea hacer alguna glosa sobre el régimen legal de concesión de televisiones privadas?

6. ¿Cómo valora el nivel de independencia de la prensa, radio y televisión privada de nuestro país tras la incidencia en la misma de la crisis económica? ¿Ve viable que desde el ordenamiento jurídico se puedan aportar terapias al respecto o entiende preferible la neutralidad del legislador?

\section{ENCUESTADOS}

MARC CARRILLO LÓPEZ, Catedrático de Derecho Constitucional, Universidad Pompeu Fabra

TOMÁS RAMÓN FERNÁNDEZ RODRÍGUEZ, Catedrático de Derecho Administrativo, Universidad Complutense de Madrid

ENRIQUE LINDE PANIAGUA, Catedrático de Derecho Administrativo (A), Universidad Nacional de Educación a Distancia

MARÍA SALVADOR MARTÍNEZ, Profesora Titular de Derecho Constitucional, Universidad Nacional de Educación a Distancia

JUAN JOSÉ SOLOZABAL ECHAVARRÍA, Catedrático de Derecho Constitucional, Universidad Autónoma de Madrid.

IGNACIO VILLAVERDE MENÉNDEZ, Catedrático de Derecho Constitucional, Universidad de Oviedo.

\section{RESPUESTAS}

1. En qué medida cree importante que la sociedad democrática avanzada que la C.E. desea establecer ha de lograr un sistema politico representativo atento a 
una opinión pública libre? $Y$ ¿qué nos quiere decir sobre el papel que juegan y/o deberían jugar los medios de comunicación públicos y privados en la difusión de información veraz y en la acogida de opiniones para la formación de una opinión pública libre?

\section{MARC CARRILLO LÓPEZ}

El resultado de las primeras elecciones democráticas del 15 de junio de 1977 y la Constitución de 1978 supusieron el primer punto de ruptura política y jurídica con la dictadura franquista. La norma suprema sentó los principios y reglas del sistema democrático a través del reconocimiento de la división de poderes y la garantía de los derechos y libertades. Entre ellos, los derechos a la libertad de expresión y el derecho a comunicar y recibir información veraz (art. 20.1 a y d CE). Desde sus primeras sentencias, la jurisprudencia del Tribunal Constitucional subrayó la condición del derecho a la información como pilar del sistema democrático. La STC 12/1982 (FJ 3) fue, sin duda, la decisión de referencia sobre la importancia que para la sociedad democrática tiene este derecho fundamental del artículo 20 y cuya argumentación conviene evocar de nuevo. Y ello para poner de relieve los déficits que en la actualidad presenta el funcionamiento de los medios de comunicación públicos y privados cercanos ya los cuarenta años de vigencia del texto constitucional.

«El art. 20.1 de la Constitución [...]. Sin embargo, en otro plano significa el reconocimiento y la garantía de una institución política fundamental que es la opinión pública libre, indisolublemente ligada con el pluralismo político, que es un valor fundamental y requisito del funcionamiento del Estado democrático. El artículo 20 defiende la libertad en la expresión de las ideas y los pensamientos y en la difusión de noticias es necesaria premisa de la opinión pública libre».

Este era y es el parámetro que la jurisdicción constitucional estableció en 1982 acerca del significado del derecho a la información y del papel que habían de jugar los medios de comunicación en la sociedad democrática. La jurisprudencia constitucional posterior conformó con mayor precisión todo un conjunto de reglas interpretativas al respecto, algunas de las cuales pueden resumirse en los términos que siguen.

La trilogía que teóricamente caracteriza la actividad de los medios de comunicación, en especial los de naturaleza audiovisual, de informar, formar y entretener, ha de ser llevada a cabo con respeto a los mandatos constitucionales del Estado democrático. A saber: separar la opinión de la información; comunicar información de forma diligente, es decir, con escrupuloso respeto a las normas de deontología profesional que impiden difundir los meros rumores o las simples especulaciones; respetar el pluralismo en todos sus ámbitos (político, cultural, lingüístico, 
etc.) garantizar los derechos al honor, intimidad y propia imagen de las personas, que en todo caso han de quedar condicionados al interés público de la noticia o a la relevancia pública de la persona objeta de la información; asegurar la crítica a poderes e instituciones aunque sea molesta o incluso hiriente, si con ello se contribuye al debate público en una sociedad plural; preservar los derechos específicos de sectores sociales especialmente vulnerables, como es el caso de los menores de edad; el respeto a los límites en el uso de los mensajes publicitarios, etc.

Atenerse a estas reglas no era ni es una cuestión banal para los medios de comunicación, presenta una especial relevancia y en todo caso, constituye también un canon para medir la calidad de la democracia de un país, verificar como se expresan y como informan tanto los medios de comunicación de titularidad pública, como los de carácter privado. Pero con la perspectiva que ofrece el transcurso de más de tres décadas de sistema constitucional, el balance a realizar ofrece más sombras que luces. Si bien los medios de comunicación públicos y una parte de los privados fueron, en general, un actor político que coadyuvó favorablemente al restablecimiento del sistema democrático a través de una relación de complicidad con los partidos políticos emergentes, la vida en libertad ha ofrecido déficits importantes que contrastan con las reglas jurisprudenciales que el Tribunal Constitucional estableció en sus primeros años de andadura institucional.

Desde la perspectiva actual pueden citarse algunos ejemplos de estas sombras. El papel actual de la prensa escrita y su imprescindible versión digital se ha visto progresivamente afectado por los demoledores efectos de la crisis económica y financiera que se inicia a partir de 2007. A fin de sobrevivir, su evidente dependencia de las entidades financieras — algunas de las cuales disponen incluso de una decisiva presencia en los consejos de administración- ha provocado que la línea editorial se resienta notablemente. Pero más allá de este aspecto sobrevenido de orden estructural que, no obstante, no parece que vaya a ser precisamente coyuntural, cabe resaltar otros de naturaleza profesional que conciernen al funcionamiento cotidiano de la prensa escrita. Así, por ejemplo, cabe registrar en algunos casos la explicita adscripción, sin especiales escrúpulos, de alguna prensa escrita a posiciones claramente adscritas al partido del Gobierno o a la misma formación política cuando estaba en la oposición en las Cortes Generales. Y no solamente en el ámbito estatal sino también en el autonómico.

Esta circunstancia se ha manifestado de manera todavía mucho más intensa y con muy pocos matices en los medios audiovisuales, dada la obvia relevancia de la televisión como instrumento más directo de poder político. En este sentido, no es ninguna osadía constatar el funcionamiento de algunos medios públicos de comunicación como auténticas correas de transmisión de la política informativa y de los proyectos políticos del partido gobernante. Ello ha sido así en buena parte de la televisión pública, tanto estatal como autonómica, con mayor o menor grado de subordinación a las directrices políticas y con algunas que otras loables pero siempre ocasionales excepciones. Incluso en radio-televisiones creadas inicialmente con unos encomiables parámetros de calidad y como vía para la recuperación de la 
identidad cultural y lingüística, pero que posteriormente se han deslizado por una pendiente de sumisión a criterios de oportunidad política y con evidente dejación de las reglas básicas de comportamiento profesional, en el ejercicio del derecho a comunicar información y del valor constitucional de pluralismo.

A este déficit hay que añadir la aparición de la patología de los llamados juicios paralelos, especialmente a través de esta excrecencia que son una buena parte de las tertulias televisivas y radiofónicas, donde unos sujetos opinan sobre todo siendo ignorantes de la mayoría de las cosas sobre las que se manifiestan. La mayoría de las veces, con un obsceno desprecio por los derechos de la personalidad de los destinatarios (honor, intimidad, propia imagen), así como de su derecho a la presunción de inocencia. Y siguiendo con los déficits de los que son especialmente tributarios los medios audiovisuales de gestión privada en programas de entretenimiento, pero respecto de los que lamentablemente los públicos no quedan exentos de responsabilidad en la práctica de la zafiedad y la vulgaridad como regla de comportamiento de los intervinientes, con notoria abstracción de los mandatos legales del Derecho europeo, estatal y autonómico, sobre garantía de los derechos de la personalidad y de protección de sectores sociales más vulnerables, así como de las normas de reguladoras de la publicidad comercial.

\section{TOMÁS RAMÓN FERNÁNDEZ RODRÍGUEZ}

Es, efectivamente, muy importante para una sociedad democrática avanzada que el sistema político representativo permanezca atento a una opinión pública libre. El problema es precisar qué se entiende hoy por opinión pública libre.

La pregunta hace referencia a los medios de comunicación públicos y privados que hasta ahora han sido el cauce de expresión de aquélla.

En lo que se refiere a los públicos, el artículo 20.3 de la Constitución marca la pauta a seguir y garantiza el respeto al pluralismo, lo que se traduce en la designación parlamentaria de los miembros del Consejo de Administración de la sociedad estatal Corporación de Radio y Televisión Española (artículo 11 de la Ley de 3 de Junio de 2006) y en la aprobación por las Cortes de un mandato-marco para dicha sociedad cada nueve años (artículo 4 de la misma Ley).

Se mantiene, pues, la fórmula del pluralismo interno que se estableció cuando la televisión estatal era un monopolio por razones técnicas y económicas. Habría, pues, que pensar si esta fórmula debe mantenerse tal cual en un sistema de libertad en el que «hacer televisión» está ya al alcance de cualquiera.

\section{ENRIQUE LINDE PANIAGUA}

A) La pregunta que se formula exige pronunciarse sobre uno de los conceptos que la integran, el de «opinión pública». Por mi parte, me adscribo a la 
posición doctrinal que niega la existencia, en las sociedades occidentales, de una «opinión pública». Y esto aunque se llegara a la conclusión de que bajo esta denominación se contemplara la existencia de una pluralidad de opiniones de los ciudadanos sobre distintos acontecimientos, sobre las políticas del Gobierno, sobre los partidos políticos y un sin fin de acontecimientos, personas y problemas sociales y políticos. Los sistemas de encuestas para conocer la opinión de los ciudadanos son escasamente fiables y, en la mayoría de las ocasiones, en vez de dar a conocer la opinión de los ciudadanos sirven o se proponen conformar la opinión de los mismos. Y por lo que se refiere a los medios de comunicación en demasiadas ocasiones pretenden configurar la opinión de los ciudadanos en vez de reflejarla.

Sin embargo, estaría de acuerdo en interpretar la pregunta en el sentido de si una democracia representativa debe estar atenta a la pluralidad de opiniones libres de sus ciudadanos. Y la respuesta sería claramente que sí. En los sistemas democráticos representativos los titulares de los poderes públicos deben tener en cuenta las opiniones de sus ciudadanos, que no deben confundirse con la opinión publicada por los medios de comunicación. La cuestión es ¿cómo pueden conocer los poderes públicos la opinión de los ciudadanos? Y ¿hasta qué medida deben tenerlas en cuenta? ¿Puede establecerse alguna vinculación de los poderes públicos a la opinión mayoritaria de los ciudadanos con posterioridad a su pronunciamiento en las correspondientes elecciones en los distintos niveles de gobierno?

En las antiguas concepciones democráticas, que llegan hasta nuestros días, los representantes de los ciudadanos elegidos en las urnas no contraían otra obligación con aquellos que la que derivaba de someterse al escrutinio de las urnas tras cada período legislativo. Los representantes no consideraban necesario rendir cuentas a lo largo de sus mandatos, y hacían oídos sordos a las opiniones y quejas resultado del incumplimiento de los programas electorales, emplazando a los ciudadanos a expresar su veredicto en las siguientes elecciones.

Las viejas concepciones democráticas, que en mayor o menor grado todavía persisten, debieran calificarse más adecuadamente como democrático-oligárquicas, en la medida en que los gobernantes aplican dos principios. De una parte consideran a los ciudadanos no tanto como los propietarios del poder, de los que los gobernantes deben ser vicarios, sino que los consideran como gobernados; un estatus que se aproxima al de los menores de edad en relación con sus progenitores. La concepción jerárquica de la sociedad es evidente en esta concepción. Por otra parte, y derivada del mencionado estatus, los gobernantes tienen entre sus poderes el de adoptar decisiones que afectan a todos los ciudadanos aunque sean contrarias a la voluntad de éstos. En esta concepción, la superioridad de los gobernantes les permitiría adoptar decisiones en la medida en que serían los titulares y custodios de valores superiores como «la nación» o el «interés general» y otros tantos, inaprensibles por el resto de los mortales. En tiempos recientes tenemos el ejemplo del presidente Aznar que se sumó a la guerra de Irak teniendo en contra la inmensa mayoría de la población, y el del presidente Rodríguez Za- 
patero, con la modificación del artículo 135 de la Constitución, eludiendo el debate sobre una modificación que ha afectado de manera sobresaliente a la vida de los ciudadanos.

A los gobernantes de un sistema político representativo solo les gusta la opinión publicada cuando les es favorable y les disgusta en todos los demás casos, por la sencilla razón de que a todo gobernante le molesta la existencia de límites al ejercicio del poder. Y por esa misma razón la existencia de ciudadanos libres capaces de formarse una opinión fundada de los problemas de sus respectivas sociedades, resulta imprescindible en una sociedad democrática avanzada.

$Y$ esto porque una sociedad democrática avanzada se debiera caracterizar porque las personas se convirtieran en ciudadanos, dejando de ser gobernados por los poderes públicos que se convertirían en servidores de aquellos. La servidumbre de los que ejercen el poder es creciente, las leyes de transparencia comienzan a proliferar, los sistemas de incompatibilidades son cada vez más estrictos, el rigor penal de las conductas corruptas es creciente y los controles internos del ejercicio del poder se incrementan considerablemente. El ejercicio del poder comienza a ser una carga en vez de un privilegio.

Y en esta concepción de una sociedad democrática avanzada, en la medida en que sea posible conocer la opinión de mayorías y minorías de ciudadanos, hay que preguntarse ¿debe ser tenida en cuenta por los poderes públicos y en qué medida? Y esto nos conduce a la consideración de dos vertientes, por una parte ¿cómo es posible conocer las opiniones de los ciudadano?, y por otra ¿hasta dónde deben ser tenidas en cuenta dichas opiniones?

Hay que diferenciar la opinión pública de la opinión publicada. Lo que opinan los ciudadanos libremente solo puede obtenerse mediante la realización de encuestas fiables de modo periódico. Las desviaciones considerables de las encuestas electorales en relación con las elecciones ponen de manifiesto que en España, aunque no solo entre nosotros, la fiabilidad de las mismas dista mucho de serlo. Las encuestas realizadas por organismos públicos pudiera ser la solución pero para que fueran fiables sería necesario dotar a dichos organismos públicos de una independencia que en la actualidad no tienen. De manera que los poderes públicos en nuestro país tienen un problema considerable para tener en cuenta la opinión pública, cual es el de conocerla.

La opinión publicada se ha convertido tras la aparición de Internet en un conjunto de gran complejidad, prácticamente inescrutable. Por una parte, la prensa, radio y televisión son creadores y difusores de opinión. Y expresan una gran fragmentación de la misma. Pero junto a lo que podríamos denominar medios clásicos de difusión la aparición de Internet ha supuesto la posibilidad de que cualquier persona capaz de crear una página web puede expresar su opinión y crear opinión y puede hacerlo por escrito pero también creando «televisiones y radios de Internet», que escapan a los controles que soportan las televisiones y radios públicas y privadas. La situación actual se podría con bastante razón calificar de caótica. La sociedad que nos ha precedido tenía como patrón de entendi- 
miento, la jerarquía, lo que alcanzaba a la opinión publicada. Los medios de comunicación clásicos más que transmisores eran configuradores de la opinión de los ciudadanos de acuerdo con intereses económicos y políticos, y ahora siguen siéndolo. El fin del oligopolio de la libertad de expresión supone la iniciación de una nueva etapa en que los poderes públicos tienen que utilizar un conjunto de instrumentos para conocer la opinión de los ciudadanos: encuestas, medios de comunicación, Internet en general y redes sociales en particular.

La otra cuestión que subyace en la pregunta es la de la asociación entre sistema representativo y opinión pública. ¿Acaso las nuevas tecnologías pueden suponer un viraje del sistema representativo a un sistema más participativo de los ciudadanos? Este, probablemente, será un escenario de debate en un futuro inmediato, el de cómo se puede implicar en el gobierno a los ciudadanos más allá de los raquíticos e inutilizados instrumentos actuales (consultas e iniciativa legislativa popular). ¿Pero puede concebirse un sistema de consultas fiables a los ciudadanos a través de Internet, por ejemplo? ¿Acaso no entraña más dificultades que ventajas? Son preguntas para las que no tengo respuestas, por el momento. El sistema representativo se ha utilizado por los gobernantes, salvo honrosas excepciones, como una carta en blanco que permite a los gobernantes incumplir los programas electorales y hacer caso omiso a los ciudadanos; es el axioma de «pídame Ud. cuentas en las próximas elecciones». Pero a mi juicio esta conducta es una manifestación de una concepción oligárquica del poder.

De manera que podría concluir diciendo que los poderes públicos durante las correspondientes legislaturas deben tener en cuenta la opinión de los ciudadanos, la de la mayoría y la de las minorías para realizar el ambicioso proyecto de gobernar para todos. Desde luego, me parece muy reprobable no escuchar a los ciudadanos una vez obtenido su voto, considerando que su único derecho es el de pronunciarse sobre los poderes públicos en las elecciones democráticas que se convoquen regularmente.

B) Los medios de comunicación clásicos (prensa, radio y televisión) aunque no tengan ya el oligopolio de la información siguen teniendo el peso más considerable en la formación y difusión de la opinión de los ciudadanos, y una gran influencia en los gobernantes. En la actualidad, además, los medios clásicos han entrado en Internet en el que publican versiones de sus periódicos, y transmiten emisiones radiofónicas y televisivas. De manera que pueden seguir siendo instrumentos de gran utilidad para difundir fragmentos de opinión, opiniones publicadas que podrían ser compuestas por los poderes públicos para, en una tarea nada fácil pero no imposible, averiguar las opiniones de los ciudadanos. Pero lo cierto es que los medios de comunicación no son fiables como representación de la opinión de los ciudadanos, son fundamentalmente medios que tienen como finalidad configurar la opinión de sus usuarios y, sobre todo, influir en los poderes públicos.

La otra vertiente es la de la transmisión de una información veraz por los medios de comunicación, igualmente importante para que los ciudadanos pue- 
dan formarse una opinión libre. En este punto, los medios de comunicación debieran cumplir lo preceptuado por la Constitución, pero tanto en España como en el resto de Occidente el postulado de la información veraz no figura entre los objetivos principales de los medios de comunicación, particularmente como consecuencia de la interpretación de la libertad de expresión e información realizada por el Tribunal Constitucional.

Pero no debe obviarse la relación directa que los ciudadanos pueden tener con los poderes públicos. Con anterioridad a la aparición de Internet los medios de comunicación clásicos se constituyeron en los únicos intermediarios entre los poderes públicos y los ciudadanos. Suministrar a los ciudadanos información veraz es una exigencia de las sociedades democráticas. Sin información veraz los ciudadanos no pueden ser libres y, en consecuencia, expresarse libremente.

Pero para que los medios de comunicación cumplan dicha función debieran producirse algunos cambios en el modo de ofrecer la información a los ciudadanos. En particular sería necesaria la obligación de que los medios crearan consejos de redacción plurales que garantizaran una información veraz, más allá de la legítima línea editorial del medio en cuestión. Lo que en todo caso no es de recibo es confundir constantemente información y opinión, que parece ser la norma en los medios de comunicación españoles y probablemente occidentales.

\section{MARÍA SALVADOR MARTÍNEZ}

A) En cuanto a la primera pregunta, de acuerdo con la construcción teórica en la que se apoyan los Estados democráticos de nuestro entorno, y el nuestro propio, la opinión pública libre constituye un requisito imprescindible para el desarrollo de dichos Estados. La democracia como forma de Estado presupone el principio de la soberanía popular y exige que el Estado se organice de tal modo que el ejercicio del poder por parte de ese Estado pueda predicarse siempre y sin excepción de su titular, el pueblo; es decir, debe organizarse de manera que la atribución de ese poder a los distintos órganos del Estado, su legitimación y su control correspondan a los ciudadanos. Para ello se establece un diseño organizativo concreto (composición de órganos, procedimientos de toma de decisiones, distribución de funciones...) y unas determinadas formas de participación de los ciudadanos. Por eso decimos que el principio democrático es un principio estructural del Estado, un principio estructurante relativo a la titularidad y al ejercicio del poder estatal.

Organizado así el Estado democrático, la formación en él de la voluntad política es el resultado de un proceso continuo que tiene lugar tanto en la sociedad como en los órganos del Estado. Los ciudadanos forman su opinión individual sobre los asuntos públicos; esa opinión, a través de los mecanismos que existen de articulación y agregación de intereses se transforma en «opinión u opiniones públicas»; y, finalmente, esa opinión pública influye, en mayor o menor grado 
— esto depende de muchos factores_- en la formación de la voluntad del Estado. Este proceso, que va de la sociedad al Estado-aparato, es el que permite la legitimación y el control del ejercicio del poder político, que son la esencia de cualquier sistema democrático. Por ello, «atender» a la opinión pública, como dice nuestra Constitución, es condición indispensable de la existencia y correcto funcionamiento de un Estado democrático.

Sobre lo dicho quisiera hacer dos observaciones. En primer lugar, no creo que hoy en día podamos hablar, como en el primer constitucionalismo, de «una» opinión pública. En aquel momento, gracias al sufragio censitario, los ciudadanos que participaban en los asuntos públicos tenían unos intereses suficientemente homogéneos, que confluían sobre todo en la idea de limitar la actuación del Estado, y por eso podía hablarse de la existencia de «una» opinión pública. En los Estados democráticos actuales, sin embargo, la sociedad no tiene una única opinión ni una única voluntad, sino diferentes voluntades, intereses y opiniones, a veces contrarias y en ocasiones contrapuestas; por eso «atender a la opinión pública» exige hoy el reconocimiento del pluralismo existente en la sociedad y la garantía de que la formación de la voluntad política resulte de un proceso en el que se expresen todas las diferentes opiniones de los distintos grupos sociales.

En segundo lugar, quisiera destacar que lo determinante de la opinión pública es el calificativo «libre» con el que se le adjetiva, porque la única expresión de voluntad que puede legitimar un Estado democrático es la que se ha formado libremente, tanto en el proceso que tiene lugar en la sociedad como en los órganos del Estado. A la garantía de esa libertad en el proceso de formación de la voluntad política sirven las libertades de expresión e información, derechos fundamentales que se reconocen en todo Estado democrático con un doble fundamento: por un lado, responder a la necesidad de las personas de expresar libremente lo que se piensa como condición del libre desarrollo de la personalidad; y, por otro, a la necesidad de garantizar la libertad en el proceso de formación de la opinión individual y pública de la que depende el correcto funcionamiento del Estado democrático. Siguiendo una interpretación que comparten sin desviaciones reseñables todos los tribunales constitucionales y los tribunales internacionales garantes de derechos, nuestro Tribunal Constitución así lo ha entendido desde la inicial STC 6/1981 a la que pertenece este extracto tan expresivo y tantas veces citado: «con el reconocimiento de la libertad de expresión y de los restantes derechos del art. 20 CE se garantiza el mantenimiento de una comunicación pública libre, sin la cual quedarian vaciados de contenido real otros derechos que la Constitución consagra, reducidas a formas hueras las instituciones representativas y absolutamente falseado el principio de representación democrática que enuncia el art. 1.2 de la Constitución, y que es la base de toda nuestra ordenación jurídico-política».

B) En cuanto a la segunda pregunta, a nadie se le escapa que los medios de comunicación desempeñan un papel absolutamente decisivo en el proceso de formación de una opinión pública libre. En primer lugar, porque la inmensa mayo- 
ría de los ciudadanos se forma, se informa y se entretiene a través de estos medios, y especialmente de la televisión. La media de horas diarias dedicadas a la televisión ha ido creciendo hasta llegar a las casi cuatro horas en 2013 (no conozco los datos de 2014, pero serán muy similares). En segundo lugar, los medios de comunicación desempeñan un papel absolutamente decisivo en el proceso de formación de una opinión pública libre porque no son sólo «medios» a través de los cuales se transmiten informaciones y hechos para que sean conocidas por todos los ciudadanos, sino que son, además, «factores» determinantes en el proceso de la comunicación, ya que realizan una labor de selección de lo que se va a transmitir y deciden qué, cómo y dónde se va a difundir, es decir, crean la realidad informativa que transmiten. Esto ha sido siempre así, pero hoy lo es más que nunca porque las posibilidades de acceder a datos y hechos son tales que la información es infinita y la selección imprescindible.

El caso de la televisión, además, es especial, porque, frente a la prensa y la radio, es el medio que mayor número de ciudadanos utiliza de manera casi exclusiva, y porque su capacidad de persuasión es infinitamente mayor que la de la prensa y la radio. La televisión es el medio de comunicación de masas por excelencia; se dirige a una pluralidad de receptores indeterminados, a una «masa anónima», y esto condiciona el contenido del mensaje (atraer al mayor número posible de receptores transforma el mensaje racional en emocional), su forma de elaboración, los valores que lo inspiran y, lo más importante, explica las enormes posibilidades de influencia y, en su caso, de manipulación que ofrece. La hegemonía de la televisión en el sector de los medios ha sido indiscutible desde que empezó a emitir. Hoy en día las nuevas tecnologías asociadas a internet ofrecen nuevas posibilidades de comunicación que han roto los esquemas tradicionales, pero, aun así, creo que la televisión sigue siendo, y será durante un tiempo aún, el medio dominante.

Bien, si ésta es la realidad de los medios de comunicación, en la que creo que podemos estar de acuerdo, con matices si acaso, y si los medios son determinantes para garantizar que haya, o no, un proceso de libre formación de la opinión pública ¿tiene la Constitución algo que decir sobre la función o el papel que deben cumplir estos medios? En mi opinión, claramente sí. El principio democrático (art. 1.1 CE) y los derechos fundamentales implicados en el proceso de la comunicación (art. 20 CE) exigen al legislador que establezca un determinado régimen de los medios de comunicación, de modo que éstos puedan garantizar un proceso libre de formación de la voluntad individual y pública; de ello depende, como sabemos, el correcto funcionamiento democrático del Estado. También entiendo que, a la hora de abordar esta tarea, el legislador debe atender a las características propias de cada medio, porque entre ellos existen diferencias relevantes que determinan y condicionan el papel que desempeña cada uno en el proceso de la comunicación.

Llegados a este punto, el problema está, a mi juicio, en que en nuestro país no se ha desarrollado el suficiente debate doctrinal y jurisprudencial para, razo- 
nando desde los arts. 1 y 20 de la Constitución, determinar sobre cuáles son los mandatos y obligaciones que de ellos derivan para el legislador en orden a establecer un régimen de los medios que garantice la libre formación de la opinión pública. El Tribunal Constitucional en la STC 6/1981 reconoció que «la libertad de los medios de comunicación (...) entraña seguramente la necesidad de que los poderes públicos, además de no estorbarla, adopten las medidas que estimen necesarias para remover los obstáculos que el libre juego de las fuerzas sociales pudieran oponerle. La cláusula del Estado social y, en conexión con ella, el mandato genérico contenido en el art. 9.2 imponen, sin duda, actuaciones positivas de este género»; sin embargo, no desarrolló esta idea en posteriores sentencias ni la concretó en obligaciones específicas para los poderes públicos. Frente a esto, en otros países de nuestro entorno, entre los que creo que Alemania es el mejor ejemplo, se ha desarrollado un intenso e interesante debate doctrinal y jurisprudencial y existe una dogmática suficientemente consensuada sobre cuál es el «régimen constitucional de los medios de comunicación».

\section{JUAN JOSÉ SOLOZABAL ECHAVARRÍA \\ (Respuesta conjunta a todas las preguntas de la encuesta)}

La consideración sobre la situación de los medios puede llevarse a cabo en tres niveles de reflexión. Podemos movernos en el nivel de la teoría constitucional; en el nivel de la realidad social; o finalmente en el nivel normativo, atendiendo a la regulación que en el Estado constitucional español se ocupa de los mismos.

1. Por lo que hace al primer nivel, los medios - hablemos de la prensa escrita o la digital, la radio o la televisión- son un contribuyente fundamental a la formación de la opinión pública y desde ese punto de vista un integrante imprescindible de la sociedad democrática. Hay otros afluyentes a la opinión pública, entendiendo por tal la idea o actitud preferente en la comunidad sobre los asuntos públicos, como son los que se derivan del ejercicio de los derechos de participación o las libertades públicas, así el derecho de reunión o asociación o las diversas muestras de la libertad ideológica, pero los medios son un componente indefectible de la opinión pública. El Tribunal Constitucional español se ha referido, como el Tribunal Constitucional alemán, con frecuencia a la contribución imprescindible de la misma al funcionamiento del Estado democrático (STC 61/1981). La democracia como ningún otro sistema es, como dijera Dicey, «un gobierno de opinión», un sistema donde los gobernantes «buscarán la opinión popular, confiriéndole peso, si no se trata del factor determinante de sus decisiones, de modo que quienes estén fuera del gobierno dispongan del derecho a ser oídos» (Key).

La opinión pública constituye sin duda el elemento plebiscitario de la democracia, de modo que el principio democrático tiene dos manifestaciones: el plano, pautado, regular y ordenado, de la organización del Estado, a través de cuyos poderes se produce la intervención del pueblo en los asuntos públicos; y otro 
plano informal o espontáneo que es el de la opinión. A la opinión pública, según la mejor teoría constitucional, le corresponden en democracia tres funciones: las dos primeras se refieren a su rendimiento, individual u objetivo, ya hablemos de la legitimación, pues el individuo, sintiéndose participante del consenso o la cultura constitucional, interviene en el plano simbólico de la integración; o nos refiramos a la eficacia, pues el sistema se refuerza objetivamente y los mandatos de las autoridades se aceptan más fácilmente si se corresponden con las demandas de la opinión. Si hacemos caso a Walter Bagehot a través de la opinión pública se produciría la contribución popular a la parte simbólica (dignified) del orden constitucional, que completaría la contribución de los ciudadanos a la organización del estado (efficient Constitution). Por descontado que la relación entre la opinión pública y los órganos del estado no obliga a estos a convertirse en ejecutores de la misma. Tampoco se encuentran, opinión y poderes públicos, vinculados jurídicamente entre sí: se trata de una orientación fáctica que permite actuaciones contrarias a la opinión pública, pero que a la larga no son mantenibles si el Estado no es capaz de conseguir que sean aprobados por ella (Zippelius).

La opinión publica cumpliría sobre todo, en tercer lugar, la función del control. Habría en la democracia dos tipos de control: un control interorgánico, de pesos y contrapesos entre los poderes del Estado; y un control no institucional, preferentemente social, de carácter esencialmente no reglamentado que, como insinuábamos hace un momento, se desarrolla fuera de pautas o límites rígidamente establecidos.

La actuación de los medios en la democracia es inevitable, pues ella simplifica, tematiza y articula la opinión pública. Los medios sugieren los tópicos sobre los que se discute y presentan las alternativas de su tratamiento. Diríamos también que los individuos participan en el debate nacional a través de los medios, apoyando determinadas voces, pues las distintas cabeceras responden sin duda a las expectativas de resonancia. De algún modo, el mercado de los medios refleja la opinión pública, pues los soportes no relevantes acaban por desaparecer. Los medios, con todo, no son transmisores inocentes sino filtros ciertamente orientados ideológicamente, aunque su poder no puede ser exagerado, pues a su vez su influencia está condicionada, especialmente por grupos primarios que quizás son los que determinan las posiciones particulares y por la existencia de otros medios competidores que pueden producir cierta compensación.

2. Contra este modelo de los medios en una sociedad democrática habría que encarar la situación efectiva de los mismos en España. Lo que ocurre es que aquí la perspectiva del jurista no resulta la más adecuada, pues de lo que habría que hablar es del grado en que la prensa española cumple esas funciones que le corresponden en la teoría constitucional, así por ejemplo la de ser un cauce adecuado para la formación de la opinión pública. Podríamos, por supuesto, dar cuenta de las condiciones para cumplir esa función, cuestionándonos si están a aseguradas jurídicamente la libertad y el pluralismo de los medios. Al respecto 
no cabe duda de que estas condiciones se cumplen, en la medida que los medios carecen de trabas en el desempeño de su labor y no hay obstáculos a la creación de los soportes de comunicación. Pero ¿de verdad que la pluralidad de medios es suficiente, de modo que no quedan sectores de la opinión sin su cobertura correspondiente? Si la cuestión fuese saber si los medios cumplen de modo eficiente con su función de control, habría que atender a la cualificación profesional de quienes trabajan en los mismos, ¿es buena la calidad de nuestros medios? La competencia en el cumplimiento de las funciones atribuidas a los medios en una sociedad democrática no depende obviamente de limitaciones o exigencias jurídicas, sino sobre todo de los planteamientos de los propios profesionales estableciendo en su trabajo cánones de exigencia, probidad y laboriosidad. No puedo decir mucho sobre estas cuestiones; supongo que un diálogo entre las facultades de periodismo y los profesionales será de mucho interés a la hora de mejorar la formación de los periodistas. También supongo que los estatutos de las redacciones, asegurando la libertad interna de prensa e introduciendo la audiencia de los periodistas en la promoción y garantía de los puestos de trabajo merecería ser considerada.

Mi opinión sobre la situación de los medios españoles no es buena. Creo que en general tienden a apreciar en términos desorbitados su relieve público, quizás alentados por una jurisprudencia constitucional que ha conferido precipitadamente una posición preferente a la libertad de prensa, descuidando que también los otros derechos son imprescindibles en una sociedad democrática, y por ello disponen asimismo de un relieve institucional obvio. Desde esta perspectiva entiendo que el combate entre privacidad o derecho al honor y libertad de expresión tiene, de antemano y por término general, un claro perdedor. Entiendo, asimismo, que otros bienes constitucionales como el secreto del sumario o la presunción de inocencia no están suficientemente asegurados en la práctica periodística. Veo que la autocrítica o rectificación jamás se practica por los periodistas; en realidad es inconcebible.

Pero lo más preocupante es la situación de la prensa seria que tiene una alineación política indudable que contrasta con la posición de este tipo de medios en otros países. Nuestros periódicos siempre están en campaña, y carecen, de ordinario, de la objetividad en un grado asombroso. Es penoso que las informaciones y editoriales necesiten de un correctivo que rebaje su parcialidad y, muchas veces, sectarismo. No sé cuál es la causa de esto: quizás la difícil situación económica de los medios, agravada por la invasión de la prensa digital, les fuerza a buscar la audiencia a cualquier precio incurriendo en el sensacionalismo, la simplificación y el escándalo, ignorando la compensación que, al menos en otros países, tiene el periodismo de calidad, basado en la profesionalidad y la probidad. El periodismo de investigación es caro, pero los medios cada vez prescinden más de él, descansando en la opinión, breve y esquemática, sobre el análisis y la objetividad.

Creo que el correcto significado político de los medios es ignorado o tergiversado en su esencia, desconociéndose cabalmente su posición institucional en la democracia, y que cada vez más se tienden a ver como un instrumento de presión o de actuación directa en la escena pública. No es necesario poner ejemplos, pero 
en ese sentido la toma de posición en el debate soberanista catalán de un medio sobresaliente es bien expresiva de una politización que en otro país, y entre nosotros en otra situación, resultaría inconcebible.

Finalmente una nota sobre la publicidad institucional que juega un papel importante sobre todo en el mantenimiento de algunos medios de prensa regional en España. Sencillamente no debería existir. O es inútil, pues lo que hace el gobierno se expone en el parlamento, de modo que el altavoz adicional de la prensa sin contraste por la oposición no tiene justificación; o es propaganda que no tiene sentido alguno en un sistema en el que debe reconocerse la igualdad institucional de todas las fuerzas en el debate político sin posición preferente para nadie, mucho menos para el gobierno, por cuenta de quien se publica la propaganda institucional. También carece de justificación la compra institucional de ejemplares de periódicos, a distribuir gratuitamente, por ejemplo en universidades, medios de transporte, etc. Representan una ayuda arbitraria a determinadas cabeceras, suponemos que a cambio de asegurar determinado comportamiento del medio, de manera privilegiada o, en todo caso, sin la transparencia debida. Ambas prácticas aberrantes suponen un derroche presupuestario intolerable.

3. Si el plano que elegimos para realizar nuestras observaciones es el plano normativo convendremos en que la densidad regulativa donde se da sobre todo es en el terreno de la radiodifusión y la televisión. Lo que haremos entonces es centrar el objeto de análisis sobre tal materia en la radio televisión pública, descuidando otros ámbitos en los que la intervención del legislador no es abundante, lo cual no tiene nada de extraño pues la libertad de expresión es sobre todo un derecho autonomía, sobre cuyo régimen el legislador, si no es con un propósito tuitivo o penal, tiene poco que decir.

La ley que regula el sector de la radiodifusión y televisión es la Ley 7/2010 de 31 de marzo General de la Comunicación Audiovisual (LGCA) que modifica y deroga las anteriores, normativas al respecto, especialmente la ley 17/2006, de 5 de junio de la Radio y Televisión Estatal y, sobre todo la Ley 8/2009 de 28 de agosto de Financiación de la Corporación RTVE. La LGCA tiene un propósito sistematizador y omnicomprensivo evidente y debe entenderse, además de cómo básica, de acuerdo con el artículo 149.1.27 CE, como la respuesta también a la las recomendaciones y decisiones comunitarias europeas, según asimismo experiencias de otros países de nuestro entorno, hablemos de Gran Bretaña, Francia o Alemania, principalmente.

La nueva Corporación RTVE se configura como una sociedad mercantil estatal única que sustituye a la Corporación de Radio y Televisión Española SA, que sucedió a su vez al Ente Público RTVE, disolviendo las dos sociedades filiales, esto es TVE y RNE. Según la Ley de 2006, la Corporación gozaba de una especial autonomía y estaba excluida del régimen común de las sociedades de capital íntegramente estatal. La LGCA convierte a la Corporación RTVE en una única sociedad mercantil a la que se encomienda la gestión directa del servicio público de la radio, televisión y servicios conexos, produciendo la extinción, y consi- 
guiente subrogación en su lugar, de las sociedades mercantiles estatales de Radio Nacional de España y Televisión Española.

La comprensión correcta de la caracterización de base de la Radio Televisón en España, de acuerdo con la LGCA, que se refiere a la calificación de la Corporacion RTVE como sociedad mercantil estatal autónoma y a su condición vehicular del servicio público de la radio y televisión, puede hacerse, con toda brevedad, de acuerdo con dos tipos de consideraciones.

A) En primer lugar, el marco conceptual en que entender la calificación adoptada es el de las administraciones independientes, entendiendo por tales organismos con funciones de regulación, control y ejecución, con fines propios y ajenos a una dirección política, lo que excepciona la comprensión ordinaria constitucional de la administración como organización meramente instrumental sin fines privativos y de cuya actuación responde el gobierno que asume su dirección. La corporación es, como sabemos, calificada, como mercantil y a una disciplina privada corresponde la inmensa mayoría de sus actuaciones, en el campo laboral o comercial. Depende en la actualidad exclusivamente de la financiación pública, y la composición de sus órganos es ajena a la intención del gobierno, dado su nombramiento parlamentario. A las Cortes, ejercido además de modo directo, corresponde asimismo su control político. Puede pensarse lo que se quiera de este tipo de instituciones que a algunos les recuerda intentos como el de descentralización funcional que en realidad se entendieron en España como pretensiones de corporativismo o ejemplos de poderes exentos. Pero también puede echarse una mirada a casos, aunque ciertamente en la realización de actividades en principio más técnicas, si bien en modo alguno fáciles o inmunes a la politización, como las referidas al proceso electoral, en que se conoce algún ejemplo de administración independiente, así la Administración electoral, presidida por una Junta Electoral Central sin dependencia jerárquica alguna del Gobierno. En la teoría constitucional algunos autores, como Rosanvallon, se han referido a las instituciones de la imparcialidad, como necesario complemento en el actual momento de crisis de las instituciones convencionales de representación. Son interesantes los apuntes morfológicos que hace Rosanvallon sobre las autoridades independientes, en relación con las formas de actuación que adoptan. Estamos hablando de comisiones o colegios, no de órganos unipersonales, esencialmente deliberativos, integrados por personalidades independientes. La independencia es función de la propia autoridad profesional de sus miembros, pero también responde a su condición inamovible y su sustitución a plazo fijo, por ello, seguramente, los mismos pueden inclinarse a ejercer «un deber de ingratitud para quienes les nombraron». La cualificación personal de los integrantes de estos organismos, puede complementarse con exigencias relativas asimismo a su representatividad social o con la garantía obligada del pluralismo político. Es muy importante la transparencia de su actuación, de modo que los dictámenes o informes de las autoridades sean públicos y objeto de amplia discusión.»No desempeñarán verdaderamente su papel si son percibidos como comités de notables o de expertos retirados en su olimpo». 
B) Problemática es, en segundo lugar, la referencia que se hace a la noción de servicio público en la caracterización de la radiodifusión y televisión, especialmente fuerte si se habla de los medios públicos. La LGCA para referirse a la comunicación servida por medios privados habla de servicio audiovisual de interés general y en el caso de la comunicación por medios públicos habla de servicio público de comunicación audiovisual. Los objetivos que se señalan a los medios de comunicación privada realmente no difieren de los especificados, con todo detalle y de manera insistente por la LGCA a los medios públicos, teniendo en cuenta por descontado que las exigencias en relación con la veracidad de las informaciones y la limitación debida a la protección de otros derechos y bienes jurídicos, como la sana formación de los niños y jóvenes, rigen tanto para los medios privados como para los públicos, lo recuerda German Fernandez Farreres, cuya contribución en el tomo editado por Santiago Muñoz Machado, «Televisión pública.En especial, la televisión estatal», así como las aportaciones en tal volumen, Derecho de la Regulación economica. V: Audiovisual del propio editor y de Marc Carrillo, como las sugerencias de diversos trabajos de María Salvador y M. Carlón, me han sido de suma utilidad para refrescar mis conocimientos sobre esta materia, — téngase en cuenta que mi estudio «Ordenación jurídica de la televisión en España» en el el n. 5 de los «Cuadernos de la cátedra Fadrique Furió Ceriol» data de 1993-. Me parece que las reticencias frente a este concepto son, honestamente, inevitables, por más que su utilización haya sido incuestionada por nuestro Tribunal constitucional (en la STC 12/1982 se señala que «la configuración de la televisión como servicio público, aunque no sea una afirmación necesaria en nuestro orden jurídico-político, se encuentra dentro de los poderes del legislador»), posición que no dista mucho de la observada por alguna instancia, incluso jurisdiccional europea.

Hoy se pone en duda la imprescindibilidad para el bienestar colectivo de la calificación de la radiotelevisión como servicio público («esencial» decía el artículo 1.2 de la Ley 4/1980 o Estatuto de la Radio y la Televisión). Además no acaba de verse por qué otras actividades igualmente relevantes para la formación de la opinión pública o incluso más como es el caso de la Prensa, no tienen esa condición de servicio público.

El recurso a esta calificación parece olvidar dos cosas. En primer lugar que han dedicado los supuestos históricos que justificaron la declaración de una actividad como servicio público en el Derecho Administrativo francés como medio de atribución a los tribunales contenciosos de la resolución de los conflictos a su prestación - por no hablar de la utilización de esta categoría como concepto central o emblemático de toda esta disciplina jurídica, por ejemplo en la obra de Duguit (Martin Rebollo)_. Ello es claro desde el momento que expresamente se atribuye la regulación, como dijimos, de las relaciones externas de los entes o sociedades que organizan el servicio al derecho privado.

En segundo lugar, que en la actualidad esta declaración servicial en modo alguno aparece demandada para justificar una intervención pública en el sector a que la misma se refiere, intervención que carecería de legitimación de no verse 
precedida de dicha declaración. Esto es ignorar la existencia de diversos títulos de actuación, se trate de regulación o incluso de gestión, que habilitarían en un Estado Social de Derecho una intervención al respecto de la administración.

En fin, en tercer lugar, la vinculación de la libertad de expresión a la noción de servicio público, no puede significar sino un rebajamiento de un derecho fundamental que queda subordinado funcionalmente de modo que pierde su originariedad y orientación individual. En tal caso la libertad de expresión no se trata de un derecho reconocido de modo inmediato y por su propio valor dependiente de su relación con la dignidad de la persona y la imprescindibilidad para el desarrollo de ésta, sino de una actividad consistente en la colaboración de un particular a la realización de una labor básica para la comunidad, que cubre o satisface un interés general y cuya titularidad originaria corresponde al Estado.

Las razones que explican el recurso a esta noción en la LGCA las ha encontrado Germán Gomez Farreres en la mejor justificación con arreglo a tal criterio, en nuestra cultura jurídica, de la financiación pública de la televisión pública, que como aludiremos en un momento reposa en dos elementos bien discutibles, hablemos de la aportación procedente de los presupuestos generales del Estado o de las que lleven a cabo los operadores de telecomunicaciones de ámbito geográfico estatal o superior al de una Comunidad Autónoma. Según lo veo, lo que permite la idea de servicio público, es una actuación particularmente intensa de la Administración en la ordenación y el control, sobre todo a traves de la atribución de la gestión indirecta de la concesión. Los reparos de tipo constitucional que ya hemos planteado quizás son rebajables teniendo en cuenta dos tipos de consideraciones: primeramente la situación de los medios privados de televisión es ciertamente lamentable en lo que se refiere a su calidad y con efectos nocivos para la calidad moral de nuestra sociedad, especialmente de su infancia y juventud, si se piensa en los objetivos banales que se proponen y en las condiciones de estupidización y disipación en las que se basan. Y segundo, que la orientación de la configuración de la televisión como administración independiente permite albergar expectativas sobre una actuación correctora de la misma, sobre todo a través de la Autoridad Audiovisual, movida exclusivamente por patrones de adecuación constitucional de las radios y televisiones sin contaminación ideológica partidista alguna.

El núcleo elemental de la problemática jurídica del sector audiovisual tiene que ver con la calificación de la Corporación RTVE como sociedad mercantil estatal autónoma y su condición vehicular del servicio público de la radio y televisión, que hemos tratado de desentrañar en sus aspectos fundamentales. Aludamos brevemente a algunas cuestiones laterales en relación con diversos aspectos del régimen del sector.

Por lo que hace a la financiación, la LGCA confirma la regulación de la ley de 2009, tratando de incorporar las consideraciones de la regulación comunitaria sobre la materia, compatibilizando la financiación pública con la prohibición de ayudas de Estado. Lo que se suscita es sobre todo el problema del cálculo de las aportaciones de los presupuestos generales del estado a la televisión pública, ex- 
clusivamente en los gastos generados por el desempeño del servicio público por parte de la televisión, utilizando el concepto de coste neto del cumplimiento de la misión de servicio público. Cuestión interesante también es considerar el posible significado expropiatorio de las aportaciones que deben realizar para el mantenimiento de la televisión pública, tras la renuncia a la financiación a través de la publicidad comercial, según la ley de 2009, las sociedades concesionarias y prestadoras del servicio de televisión de ámbito geográfico estatal o superior al de una Comunidad Autónoma.

Por lo que hace a los aspectos organizativos de la Corporación, se consolida la parlamentarización del ente, en lo que se refiere a la dirección y el consejo (Presidente y Consejo). La mayoría requerida para el nombramiento de los consejeros - doce y ahora tras el decreto-ley 15/2012 de 20 de abril nueve, de modo conjunto en el Congreso y Senado- y del Presidente en el Congreso es de 2/3, reducible a mayoría absoluta si en primera votación no se pudo alcanzar el acuerdo. Los efectos ventajosos en relación con el aseguramiento de la imparcialidad de estos órganos se reducen considerablemente si el criterio seguido para su designación no es el de encontrar personas supra partes o equidistantes sino el de reparto conforme a su peso parlamentario entre los partidos políticos.

Sobre la cuestión del aseguramiento de la garantía del pluralismo, estableciendo el derecho de acceso, seguramente es cuestionable que el mismo quede al albur de la decisión del Consejo al respecto, a pesar de la STC, que había establecido que, «El derecho de acceso, en otras palabras, será en cada caso articulado por el Legislador, pero ni éste queda libre de todo limite constitucional en dicha configuración, ni la eventual vulneración de sus determinaciones por los aplicadores del Derecho podrá decirse constitucionalmente irrelevante en orden al ejercicio eficaz de las libertades consagradas en el art. $20 \mathrm{CE}$, pues estas libertades habrán de realizarse a través de estos medios, del modo que quiere la Constitución en el apartado 3 del mismo precepto, de tal modo que la denegación discriminatoria, o arbitraria por carente de fundamento legal, del acceso que la Ley haga posible, entrañará el consiguiente menoscabo del derecho del grupo así afectado - de quienes a su través pretendan difundir las propias ideas y opinionesa la libertad que la Constitución garantiza [art. 20.1 a)]».

La constitución de la Autoridad Audiovisual prevista ya en la Ley de 2006 no se ha llevado a efecto, aunque existan instituciones semejantes en varias Comunidades Autónomas en funcionamiento. A pesar de la configuración del Consejo Estatal de Medios Audiovisuales como una institución próxima a la propia de una Administración independiente parece pertinente alertar, como hace Muñoz Machado, contra la administrativacion del control de los contenidos. Si tal control conduce a la adopción de medidas provisionales de suspensión o incluso puede acordarse el cese de los programas, «antes de que haya habido un pronunciamiento judicial constatando la vulneración constitucional» podríamos estar ante un supuesto, incurso en flagrante ilicitud constitucional, de censura previa o secuestro de grabaciones. 


\section{IGNACIO VILLAVERDE MENÉNDEZ}

Desde luego, se trata de un topoi en este ámbito el papel irrenunciable e indispensable de una opinión pública libremente formada como elemento político basilar del Estado democrático representativo. De la misma manera que el paradigma del Estado democrático se ha cimentado en la ficción de una comunidad de sujetos racionales, libres e iguales que actúan y participan en los procesos de creación y aplicación de normas sólo movidos por el ánimo de tomar la mejor decisión razonablemente posible, se ha construido, consistente con el anterior, otro paradigma de los procesos de comunicación pública sustentado en la ficción de que su finalidad es contribuir a esos procesos de decisión colectiva mediante la formación de una opinión racional que tiene como condición indispensable que los miembros de la comunidad dispongan de fuentes de información en cantidad (pluralismo) y calidad (imparcialidad e independencia). Tanto el TC como el TEDH (y en general todos los tribunales constitucionales de nuestra cultura jurídica) han importado la doctrina de la Corte Suprema de los EEUU relativa a la condición de «perro guardián» de la Democracia que ostentan los medios de comunicación en los sistemas constitucionales modernos con cuya labor informativa y de vigilancia sobre el poder político alimentan una opinión pública avisada e informada sobre los asuntos públicos. Es más, en buena medida, la teoría de los Estados democráticos representativos se construye sobre la ficción de la existencia de una comunidad de individuos, libres y todos iguales, que además son y actúan de forma racional, y participan en los procesos de creación y aplicación de las normas que la regulan mediante la expresión de opiniones informadas. De manera que a mejor información, mejores opiniones, y en esa medida decisiones colectivas más racionales. Este paradigma ha derivado hacia las teorías funcional-democráticas de la libertad de información, que han tratado de superar el modelo liberal del «libre mercado de las ideas» (STUART MILL), considerando que la libertad de información que merece una protección constitucional reforzada y privilegiada, sólo limitada por el ánimo torticero de engañar o insultar gratuitamente, es aquélla que justamente contribuye de forma activa a la formación de una opinión pública libre mediante la transmisión de información veraz sobre asuntos de relevancia pública.

Ese indiscutible papel central de la formación de la opinión pública mediante la transmisión de información veraz, puede derivar (y de hecho ha derivado en ocasiones, siendo un ejemplo el propio TC, STC 107/1988), a privilegiar a los medios en el ejercicio de su libertad de información considerando que representan a los ciudadanos en la obtención y transmisión de información, ocupando por ello un papel privilegiado; y la tendencia a confundir la opinión pública, con la opinión «publicada» (RODOTA).

Que en esa función formativa de una opinión pública informada, esencial para el funcionamiento de un sistema democrático avanzado y digno, desempeñan un papel protagonista los medios porque son ellos los que alimentan de forma más intensa y extensa los procesos de comunicación pública en los que se 
forma la opinión la colectividad de ciudadanos, es un hecho incontrovertible. Sociopolíticamente son los instrumentos más eficaces para realizar esa función de control informativo sobre el poder público y de información de los ciudadanos. De ahí que la libertad de información sea a un tiempo el «escudo» que debe proteger aquella actividad, y la «espada» en manos de los medios para lograr acceder a información relevante para el conjunto de los ciudadanos y a través suyo poner a disposición de la ciudadanía los elementos que le permitan la formación de un juicio racional sobre los asuntos públicos. Pero también la doctrina (FISS) ha llamado la atención sobre el riesgo de una libertad de información «secuestrada» por los medios de comunicación, de manera que en realidad los medios se transforman en un poder (el cuarto como decía BENTHAM), imbricado y en ocasiones cómplice de los poderes económico y político, con igual tendencia a la manipulación y al ocultamiento interesado, que puede alterar el racional y objetivo proceso formativo de la opinión pública. Una circunstancia que ha girado la vista hacia, precisamente, los medios como uno de los factores de riesgo de una ciudadanía manipulada y desinformada (apenas mitigada por internet que ha generado un nuevo ciudadano autista informacional - WINNER). De hecho, los tribunales no en pocas ocasiones han apelado a la libertad de información como límite a la actividad de los medios exigiéndoles para gozar de su escudo amparador, que la información que transmitan sea en efecto veraz, de relevancia pública y carente de expresiones insultantes, innecesarias o gratuitamente ofensivas.

De ahí que se haya vuelto a subrayar la necesidad de medios de comunicación públicos, el control mediante autoridades independientes de la actividad de los medios, limitaciones a sus procesos de concentración, imposición de estatutos de redacción y libertad de tendencia (pluralismo interno) o la aplicación de cánones estrictos en el enjuiciamiento de sus informaciones si éstas suponen revelar la privacidad de las personas o ponen en riesgo su seguridad o la de sus familias (Informe LEVINSON).

2. ¿Cabe temer que entre todos los obstáculos para que los medios cumplan bien sus funciones pueden existir interferencias o presiones a los mismos provenientes de los poderes públicos o de los partidos políticos? Si su respuesta es afirmativa: ¿puede sugerirnos tratamientos de Derecho Público para tal problema, basados en modelos foráneos o de propio cuño?

\section{MARC CARRILLO LÓPEZ}

Antes de examinar algunas propuestas que ofrece el Derecho Público a las interferencias del poder sobre los medios de comunicación, procede retener de nuevo la atención sobre los llamados juicios paralelos a los que se acaba de hacer referencia. La razón de ello se justifica en la medida que las propuestas que expon- 
dré en este apartado para hacer frente a los intentos de mediatización del poder político, también pueden servir para neutralizar los efectos de la mala práctica informativa que suponen los citados juicios en los medios audiovisuales.

Concretamente, la información sobre procesos judiciales ha puesto de relieve en demasiadas ocasiones la importancia de un hecho no tipificado en norma jurídica alguna, pero que aparece instalado como una lamentable realidad social en la vida pública española. Se trata de la retóricamente denominada pena de banquillo, considerada así por el carácter eventualmente irreparable de la lesión en el crédito social que puede suponer para una persona acudir ante un órgano judicial para declarar como imputado o incluso simplemente como testigo.

La citada pena se concreta en la situación siguiente: dado que los medios de comunicación han reflejado su imagen y han analizado y comentado de una determinada manera los motivos de su comparecencia judicial, se considera que el mero hecho de tener que acudir a un acto procesal ante un juez, puede suscitar en algunos casos una implícita condena social aun cuando el devenir ulterior del caso o de la resolución judicial — de llegarse a producir— sea absolutoria.

El juicio paralelo se produce como consecuencia del ejercicio irresponsable del derecho a comunicar información (art. 20.1.d CE), haciendo abstracción de la debida diligencia, esto es, con la ética profesional que conlleva el debido contraste de la noticia, tal como así lo ha interpretado la jurisprudencia constitucional (STC 6/1988) y obviando de forma deliberada el derecho de toda persona que comparece ante la jurisdicción ordinaria a la presunción de inocencia (art. 24.2 CE). A este respecto, se puede convenir que para la existencia de esta anomalía que es el juicio paralelo, es preciso que se haya iniciado un proceso judicial; que la información y la expresiones difundidas por los medios adelanten de alguna forma la culpabilidad o la inocencia del procesado, incitando a la opinión pública a pronunciarse en un sentido u otro al poner en práctica una acción informativa de naturaleza manipuladora; y, además, que con ello se pretenda ejercer una presión sobre la independencia de los órganos del poder judicial, de tal manera que el lector o el espectador perciban que la resolución judicial ya está prefijada por el medio de comunicación.

Esta mala práctica informativa ha llegado incluso al extremo de registrar la implicación de magistrados, como colaboradores necesarios de la misma hasta el punto de vulnerar del secreto sumarial. Ambas cuestiones requieren de una profunda reflexión, porque el respeto al derecho a un proceso debido en especial el derecho a la presunción de inocencia (art. 24. 2 CE) y la ética profesional en el ejercicio del derecho a comunicar información (art. 20.1.d CE) son dos señas de identidad indeclinables del Estado democrático.

El proceso judicial no puede ser un cheque en blanco para que el medio de comunicación convierta a aquél en pasto de información no contrastada y con finalidad sensacionalista; es decir, aquél modo de producir información caracterizado por difusión de hechos, reales o supuestos, que carecen de relevancia sobre el objeto del proceso y que no muestran una mínima y racional relación de cau- 
salidad con lo que se juzga, pero que sin duda alimenta el llamado amarillismo informativo, propio de los tabloides británicos y alemanes y del que no son ajenos determinados medios de comunicación españoles escritos o audiovisuales. El contenido de ciertos programas de televisión y la singular — por su mala calidad técnico-jurídica - cobertura informativa de algunos procesos judiciales, llevada a cabo por determinados medios, se inscribe de forma flagrante en esta manera espuria de ejercer el derecho fundamental a informar.

La patología informativa que constituyen los llamados juicios paralelos plantea diversas cuestiones de relevancia constitucional. De todas ellas, es preciso poner énfasis en las que conciernen, en primer lugar, al uso inadecuado del derecho a comunicar información con clara infracción, no sólo de normas deontológicas, sino también de las reglas que la jurisprudencia constitucional ha establecido y que los profesionales de la información no pueden ignorar, para resolver los conflictos que pueden producirse entre el derecho a comunicar información (art. 20.1,d CE) y la libertad de expresión por un lado y los derechos de la personalidad por otro (art. 18.1 CE); en segundo lugar, el uso inadecuado de la información con ocasión de un proceso judicial, puede poner en cuestión el derecho a la presunción de inocencia del procesado como parte integrante del derecho a la tutela judicial, incidiendo asimismo también y de forma negativa en el principio de independencia judicial (art. 117.1 CE); y, finalmente, cabe también plantear la cuestión de las vías más adecuadas para hacer frente a esta patología, que como criterio general, entiendo que no pueden quedar reducidas a la necesaria represión judicial de conductas antijurídicas, sino que a su vez exigen, en el ámbito de los medios audiovisuales, la intervención previa de los entes reguladores con capacidad para ejercer, en su caso, la potestad sancionadora sobre los medios que vulneren las disposiciones del Derecho europeo, estatal y autonómico, relativas a los derechos fundamentales reconocidos en los artículos $18.1,20.1, \mathrm{~d})$ y 24.2 CE.

A fin de afrontar tanto a las malas prácticas informativas de los juicios paralelos como a las interferencias o presiones ejercidas por los poderes públicos y partidos políticos, podría resultar útil disponer de una autoridad administrativa independiente reguladora del audiovisual de ámbito estatal y, en algunos casos, también de ámbito autonómico. A este respecto y como es bien conocido, el caso español ha sido una excepción en la Unión Europea. Hasta la reciente aprobación de la Ley 7/2010, de 31 de marzo, General de la Comunicación Audiovisual, (LGMA) España carecía de un órgano regulador de ámbito estatal, que tuviese encomendada la muy importante función de intervenir sobre la actividad de los medios de comunicación de carácter audiovisual.

A pesar de la modestia de las atribuciones otorgadas al Consejo Estatal de Medios Audiovisuales (CEMA) regulado en el Título V (arts. 44 a 55) de la LGMA, su creación debía suponer un punto de inflexión en un pasado en el que reiteradamente se vieron frustrados diversos intentos en la década de los noventa, de poner en marcha un órgano regulador de los medios audiovisuales con capaci- 
dad para intervenir sobre su actividad y, en su caso, también sobre los contenidos. Al objeto, sobre todo, de desvincular del Gobierno de turno la plena capacidad de decisión acerca de cuáles habían de ser los prestadores beneficiarios del servicio de comunicación audiovisual, a fin de atribuirla a una autoridad independiente de la lógica de las mayorías políticas del momento. Pero el CEMA nunca ha llegado a ver la luz y sus atribuciones han quedado absorbidas y, de hecho, diluidas, por un ente regulador, la Comisión Nacional de los Mercados y de la Competencia, regulada por la Ley 3/2013, de 4 de junio,

Pues bien, los referentes de derecho comparado que pueden ofrecerse son las llamadas autoridades reguladoras independientes. En Europa, el modelo principal entre estos entes lo ofrece, sin duda, el Conseil Supérieur de l'Audiovisuel (CSA). Pero no se puede tampoco olvidar en el ámbito anglosajón, a la Independent Televisión Comisión y en los Estados Unidos a la Federal Communications Comisionn (FCC). Centrando únicamente la atención en el primero, cabe destacar algunas de sus atribuciones que pueden resultar de interés a fin de paliar los problemas detectados en los medios audiovisuales españoles. Así, entre sus competencias más significativas destacan las siguientes: garantizar el principio de libertad en la comunicación audiovisual y para ello, al CSA le corresponde asegurar la independencia y la imparcialidad del sector público de la radiodifusión sonora y de la televisión; la libre competencia y el respeto al pluralismo; la calidad y la diversidad de los programas; el desarrollo de la producción y creación audiovisual nacional así como al promoción de la lengua y la cultura francesas. Dispone, asimismo, de funciones de regulación en materia de telecomunicaciones; nombra — para un mandato de tres años - al Presidente de los Consejos de Administración de las radios y de las cadenas públicas de televisión y ejerce el control de las campañas electorales. En especial cabe destacar que interviene en la gestión y atribución de frecuencias para la emisión de radio o televisión por ondas hertzianas y otorga la autorización para la emisión de radios FM y televisiones privadas.

Para llevar a cabo estas competencias dispone de potestad reglamentaria a través de la aprobación de reglamentos. Además puede realizar recomendaciones a los operadores y, anualmente, presenta un informe al Presidente de la República, al Gobierno y al Parlamento. Entre las medidas de carácter coercitivo que pueden tomar se han de señalar: la suspensión de la autorización, la reducción de la duración de la misma, así como también su revocación y las sanciones pecuniarias. Además puede obligar a insertar comunicados en los programas audiovisuales. Pero no solo posee un poder de decisión sino también le es reconocida una especie de magistratura de persuasión en relación a los poderes públicos (a través de sus sugerencias para modificar el ordenamiento vigente sobre el audiovisual) y los operadores privados de radio y televisión (por ejemplo, para asegurar la igualdad de trato entre los candidatos y las partidos políticos o para velar por la dignidad de la persona en los reality schow). En todo caso, sus decisiones están sometidas al control de la jurisdicción del Consejo de Estado. 


\section{TOMÁS RAMÓN FERNÁNDEZ RODRÍGUEZ}

Naturalmente que cabe temerlo. La radio y la televisión estatales están en manos de los partidos políticos representados en las Cámaras, como lo está la Justicia, cuyo Gobierno depende de un Consejo de extracción parlamentaria. Para el Consejo General del Poder Judicial sí tengo alternativa: la vuelta al sistema implantado por la Ley de 1980; para la radio y televisión estatales no tengo ninguna.

Habría que pensar en alguna fórmula que garantizara la independencia instrumentando algún sistema de participación de la sociedad a través de sus instituciones culturales.

En lo que respecta a los medios audiovisuales privados, el pluralismo queda asegurado, en principio, por la libertad, aunque me parece un poco ingenuo quedarse ahí. Tengo para mí que la televisión, pública o privada, cumple una misión de servicio público (en el sentido francés de la expresión), lo que justifica y aun exige el establecimiento de alguna medida capaz de moderar el libre despliegue de la libertad de empresa y de asegurar un cierto servicio general a la cultura.

\section{ENRIQUE LINDE PANIAGUA}

A) Considero un error cifrar en los poderes públicos o en los partidos políticos los únicos o los principales obstáculos para que los medios cumplan la función de ofrecer información veraz a los ciudadanos, así como participar en el complejo proceso de formación de la opinión libre de los mismos. En nuestro mundo globalizado la amenaza principal para la información veraz se encuentra tanto en los poderes públicos y los partidos políticos como en la propia configuración de dichos medios privados de comunicación, subordinados a intereses económicos y políticos que utilizan dichos medios de comunicación para la consecución de fines ajenos al de informar a los ciudadanos.

Pero dicho lo anterior hay que añadir que los poderes públicos no tienen, por lo general, entre sus objetivos principales facilitar a los medios el cumplimiento de sus obligaciones constitucionales. Los titulares de los poderes públicos y de los partidos políticos pretenden mantenerse en el poder, y la verdad no siempre es una aliada para conseguirlo. Pero, tras la anterior generalización debe decirse que puede establecerse una escala gradual según sean los titulares de los poderes y de los partidos políticos más o menos transparentes. Es decir más o menos democráticos.

De manera que la cuestión sería: ¿Cómo puede garantizarse el rechazo de las presiones que soportan los medios de comunicación provenientes de poderes públicos y privados? Y para contestar a esta cuestión debe contestarse a su vez a una cuestión previa. ¿Acaso los medios de comunicación tanto públicos como privados persiguen la independencia de poderes públicos y privados? Mi respuesta es 
que los medios de comunicación públicos y privados no persiguen la independencia de poderes públicos y privados. Muy al contrario son instrumentos de los poderes públicos y privados, sin que se vislumbre en el futuro inmediato que la situación que conocemos vaya a cambiar.

B) Los gobiernos estatal y autonómicos y los partidos políticos han colonizado los medios públicos de comunicación y pretenden influir en los medios privados. Especialmente grave es la colonización, a la que me gusta denominar con mayor precisión parlamentarización de las radiotelevisiones públicas. De manera que tenemos dos problemas que, más allá de las leyendas de independencia de determinados medios de comunicación, el análisis de los hechos hace que las mismas no se soporten en la realidad.

Por lo que se refiere a los medios públicos parece demostrado que la legislación española, desde la Ley de la Radio y Televisión de 1980 hasta la fecha, no han servido para impedir la injerencia de los poderes públicos en las radios y televisiones públicas. Por lo que se refiere a los medios privados las sucesivas reformas de la Ley de televisión privada de 1988 ha permitido el control de dichos medios por multinacionales que han invertido las relaciones de los medios con los poderes públicos.

No existe ningún sistema normativo que pueda garantizar la independencia y ecuanimidad de los medios al margen de un elevado nivel ético de las sociedades en que se produce. La Ley 17/2006 de la radio y la televisión de titularidad estatal dio un vuelco a la Ley de 1980 y puede considerarse como estimable. El sistema de elección de los consejeros y del presidente de la radiotelevisión española que se transfería a las cámaras y que exigía el acuerdo entre los dos grandes partidos políticos no era objetable. Ahora bien, tanto antes como después de 2006 los partidos políticos mayoritarios se repartieron y se siguen repartiendo los cargos de consejeros, parlamentarizando el Consejo de administración, y designando para los cargos de consejeros, presidentes y demás puestos directivos a militantes de sus respectivos partidos políticos sin otro mérito que no sea la lealtad. Pero si la aplicación de la Ley 17/2006 durante el Gobierno de Rodríguez Zapatero no fue virtuosa, la reforma de dicha Ley por el Gobierno Rajoy ha sido un ataque profundo a la independencia de la radiotelevisión pública estatal. Dicha reforma permite el nombramiento del presidente y consejeros solamente por el grupo parlamentario del Gobierno que tenga la mayoría absoluta en el Congreso y en el Senado, sin requerir el consenso de los partidos políticos de la oposición parlamentaria. Hemos vuelto a la situación de la radiotelevisión pública anterior a la transición democrática.

De manera que puede decirse que la ley no puede garantizar por sí sola la independencia de los medios de comunicación públicos. La redacción originaria de la Ley 17/2006 cumple la mayoría de los requisitos exigibles, pero si la ley no es aplicada por gobernantes con un alto nivel ético la ley de poco servirá, sin que a estos efectos el Tribunal Constitucional se haya sentido concernido, en contras- 
te con la reciente jurisprudencia del Tribunal de Derechos Humanos de Estrasburgo que ha erigido el pluralismo político en un principio cuyo incumplimiento permite declarar la inconstitucionalidad de leyes como las que recientemente han modificado la Ley 17/2006.

\section{MARÍA SALVADOR MARTÍNEZ}

Puesto que la capacidad de los medios de influir en la opinión y en la voluntad de los ciudadanos es determinante, con las diferencias entre unos medios y otros a las que antes nos hemos referido, los peligros o amenazas para que éstos puedan cumplir la función de garantizar la libertad en el proceso de formación de la opinión pública resultan evidentes. Poderes públicos, partidos políticos y todo aquel que participe en la lucha política y quiera alcanzar el poder político tiene en los medios, y especialmente en la televisión, una herramienta privilegiada para convencer a los ciudadanos de que su candidato o su opción es la mejor de las posibles, o que el candidato contrario y su programa son la peor alternativa. No creo necesario poner ejemplos de las posibilidades de manipulación que ofrecen los medios en este sentido. Pero éstos no son los únicos obstáculos para que los medios puedan cumplir su función. Las empresas privadas de comunicación atienden a la satisfacción de sus intereses, lo cual es perfectamente legítimo; el problema surge cuando esos intereses son contrarios a la garantía de la libre formación de la opinión pública, cosa que puede ocurrir, o cuando estas empresas ocupan una posición tan dominante en el sector que su poder de influir en el proceso de la comunicación es incompatible con la libertad y la expresión del pluralismo que el principio democrático exige.

A la vista de lo dicho, la tarea del legislador, que debe establecer un régimen de los medios que les permita actuar como garantes de la libre formación de la opinión pública, no es del todo sencilla. No obstante, las líneas definitorias del régimen de los medios en todos los países europeos son muy similares.

En cuanto a la prensa, el establecimiento de su régimen jurídico no ha supuesto un desafío para el legislador. Debido a las características de este medio, en todos los países de nuestro entorno se ha establecido un mercado libre, porque el ejercicio de las libertades de expresión e información, como derechos de libertad frente al Estado, se ha considerado tradicionalmente garantía suficiente frente a la amenaza de injerencias por parte de los poderes públicos; puede ser problemática la regulación que se haga de la publicidad institucional y de ayudas públicas de cualquier tipo, ya que pueden servir de vía de influencia de los poderes públicos. No obstante, el gran reto para el legislador es hacer frente al fenómeno de la integración de la prensa en grandes grupos empresariales multimedia mediante la aprobación de normas anticoncentración eficaces. A mi juicio, es más acertado el establecimiento de normas anticoncentración basadas en cuotas de mercado o de audiencia (cuotas de influencia en la 
opinión pública) que en porcentajes de capital, porque de lo que realmente se trata es de medir y limitar el poder de influir en la formación de la opinión de los ciudadanos. En todo caso, creo que debíamos tomar nota de cómo en otros países periódicamente se analiza la eficacia de las normas anticoncentración y se proponen reformas al respecto.

El régimen de la radio y la televisión, sin embargo, sí creo que constituye un reto para el legislador, porque el Estado no puede gestionar directamente estos medios, ni ejercer una influencia decisiva sobre ellos, pero tampoco puede dejarlos al libre juego de las fuerzas del mercado. En todos los países europeos se ha establecido un sistema dual en el que coexisten radiotelevisiones públicas y radiotelevisiones privadas. El reto es organizar la radiotelevisión pública de modo que ésta actúe de la forma más independiente posible de los partidos políticos y de la lucha política que tiene lugar en los órganos del Estado, es decir, con independencia del Gobierno y del Parlamento. En cuanto a las radiotelevisiones privadas, el legislador debe garantizar igualmente la mayor independencia posible de los emisores privados respecto del Gobierno y el Parlamento, y, como se ha dicho ya, establecer normas anticoncentración eficaces. Las diferencias entre unos países y otros en cuanto a la fundamentación constitucional, el desarrollo concreto de ese régimen jurídico y, evidentemente, la cultura política, han determinado que el grado de dependencia de poder político, el nivel de concentración de los medios privados, y la calidad del servicio que ofrecen no sean iguales en todos ellos.

A mi juicio, el modelo con un desarrollo teórico más acabado y coherente, y unos resultados aceptables, es el alemán. En el sistema dual alemán de radiotelevisión es a la radiotelevisión pública a quien le corresponde la tarea de garantizar la libre formación de la opinión pública. Para ello las radiotelevisiones públicas se han creado como organismos independientes cuyo principal órgano es un Consejo de Radiotelevisión del que forman parte representantes de los grupos sociales más relevantes, que no son sólo los partidos políticos, sino, también, y fundamentalmente, asociaciones, fundaciones, confesiones religiosas, etc. Además, para garantizar la independencia de estas instituciones, el Tribunal Constitucional las ha reconocido titulares del derecho fundamental a la libertad de la radiotelevisión (recogido en la Constitución), que ejercen frente al Estado, frente a los poderes públicos, en orden a poder cumplir la función que tienen atribuida. Esto ha hecho posible que la influencia de los partidos políticos, que, ciertamente, también existe en las radiotelevisiones alemanas, sea bastante más limitada que la existente en otras radiotelevisiones públicas europeas.

En cuantos a las radios y televisiones privadas, el Tribunal Constitucional alemán ha reconocido que no pueden cumplir la misma función que las públicas, por su propia naturaleza, ya que se trata de empresas privadas cuya programación depende de las cuotas de audiencia; a pesar de ello, deben contribuir en la medida de lo posible a la libre formación de la opinión pública, para lo cual se establecen normas anticoncentración y normas de programación que los emisores privados 
deben cumplir. La singularidad del sistema alemán consiste en que no puede ser el Estado el que adjudique las concesiones y controle la actividad de las televisiones privadas. Para desempeñar estas funciones, el legislador ha creado organismos independientes con un régimen jurídico muy similar al establecido para las radiotelevisiones públicas y a las que también se les reconoce titulares del derecho fundamental a la libertad de la radiotelevisión.

Ya sea del modelo alemán, o de otros modelos europeos, considero que existen suficientes referencias de derecho comparado si es que algún día existe voluntad real de establecer en nuestro país un régimen de los medios que garantice la libertad en el proceso de formación de la opinión pública.

\section{IGNACIO VILLAVERDE MENÉNDEZ}

Yo creo que la pregunta en el fondo expresa una consecuencia de aquella ficción según la cual la democracia se asienta en una comunidad de individuos racionales que necesitan mecanismos para formar su opinión entre los que resulta indispensable la función que le cumple a los medios de comunicación de alimentar el proceso comunicativo público en el que la comunidad forma su opinión. El corolario de esta proposición es que los medios de comunicación deben ser neutros en su función de instrumento de la formación de una opinión pública libre e informada. El caso es que en este argumento se olvida la condición ficticia del paradigma, y además, la circunstancia de que ese paradigma puede oscurecer la condición de libertad que las Constituciones occidentales han atribuido a la comunicación de información, de manera que es decisión de su titular qué y cómo informar, a riesgo, cierto, de que lo haga de manera democráticamente poco satisfactoria. El único remedio ante este riesgo es el pluralismo informativo: cuantos más participen en el proceso de comunicación pública, menos perjuicio provoca la intervención de sujetos que adulteran la información.

Modelos como el de EEUU, el francés, el británico o el italiano, en un momento u otro han regulado o tratado de regular los medios de comunicación con dos fines fundamentales: evitar los monopolios u oligopolios informativos, y limitar su capacidad para manipular la información. Lo cierto es que la experiencia comparada sólo muestra un rotundo fracaso de este tipo de legislaciones. Más eficaces han sido las políticas de ayuda a la creación de medios de comunicación, como instrumento del fomento de un pluralismo externo informativo robusto. Pero la realidad económica, siempre tozuda, ha impuesto traumáticos procesos de concentración de medios de comunicación que han vuelto a poner en cuestión estas políticas de fomento.

¿Quiere decirse con ello que el proceso de comunicación pública debe desregularse? En absoluto. Tan sólo que las estrategias regulativas sustentadas en los controles sobre la propiedad de los medios o con criterios economicistas no han resultado exitosas a la larga. Es posible que el camino deba ir en la dirección de 
fortalecer el pluralismo interno en los medios de comunicación mediante los estatutos de redacción, la instauración de autoridades independientes de control, y la regulación del derecho de acceso de terceros a ellos.

En mi opinión, en la actualidad el mayor riesgo para los medios de comunicación, paradójicamente, no proviene de los poderes públicos o de los partidos políticos, que, antes bien, sufren la presión y el control que sobre sus actuaciones ejercen los medios de comunicación, convertidos hoy en actores políticos sumamente intrusivos. El riesgo hoy, y el caso de los atentados a la redacción de la revista satírica Charlie Hebdo o las amenazas a periodistas, humoristas, actores o artistas por parte de grupos religiosos extremistas así lo ponen de manifiesto, es la progresiva imposición de una «tiranía del silencio» (ROSE) por ciertos colectivos intolerantes y reactivos a la crítica de sus creencias o ideas, con el pretexto de que deben ser respetadas sus costumbres, culturas, tradiciones, ideologías o religiones.

3. Desde nuestra realidad autonómica, ¿qué valoración le merece tanto la actual distribución de competencias en materia de medios, como el ejercicio que se ha hecho de las mismas?

\section{MARC CARRILLO LÓPEZ}

A partir de la habilitación competencial que estableció la Constitución ex art. 149.1 27, por la que al legislador estatal le correspondía la regulación de las normas básicas, en general, sobre todos los medios e comunicación social, y a las Comunidades Autónomas su desarrollo y ejecución, la Ley 46/1983, reguladora del Tercer Canal de Televisión estableció que la gestión mercantil del servicio público de televisión del tercer canal se había de realizar a través de una sociedad anónima. Esta sociedad había de estar constituida en su totalidad por capital público adscrito a la Comunidad Autónoma.

Este sistema de distribución competencial permitió la creación de las primeras cadenas de televisión en las denominadas CCAA históricas (Disp. Transitoria 2. ${ }^{a} \mathrm{CE}$ ) con la clara finalidad de dotarse no sólo de un medio de comunicación sobre la realidad territorial más cercana, sino también de un instrumento de normalización de su identidad cultural y lingüística.

La primigenia concepción de la radio y televisión como servicio público sirvió especialmente a la consecución de dichos fines, pero en algunos casos no lo fue tanto para el cumplimiento de los fines establecidos en la antigua legislación básica sobre la materia, la Ley 4/1980 del Estatuto de la Radio Televisión Española, sobre todo los relativos al pluralismo informativo. Con grados distintos de intensidad, los problemas de servidumbre con el poder político territorial empe- 
zaron a ser similares a los que ya anteriormente mostraban los medios audiovisuales estatales, también con distintos niveles de subordinación a criterios oportunidad en la información, según el color de la mayoría política.

Con el progresivo proceso de liberalización del sector, que encuentra su referente en la Directiva de Servicios o Directiva Bolkenstein en el ámbito de las telecomunicaciones (2004) y la Directiva de Servicios de Medios Audiovisuales (2007, y modificada en 2010), la inicial concepción de servicio público de los medios audiovisuales fue sustituida por la de servicio de interés general. Asimismo, en el marco de la regulación pública de estas actividades se cambió la regla y los medios audiovisuales se concibieron como «un servicio esencial de interés económico general». Con esta nueva concepción se subrayaba la importancia económica de la actividad audiovisual, pero a su vez quedaba en un segundo lugar la noción de servicio público, especialmente en lo que concierne a los contenidos, no solo de la información sino también de los programas de formación y entretenimiento.

Con la aprobación de la Ley 7/2010, General de la Comunicación Audiovisual y la posterior reforma de 2012, el proceso de liberalización del sector se ha incentivado. De un mercado restringido en el que operaban las cadenas públicas y algunas de gestión privada a través de concesión (Ley 10/1988, de la televisión privada), se ha pasado a un contexto de libre mercado, regulado por un sistema de control administrativo previo en el que la actividad privada dispone de un mayor margen de actuación. Ciertamente, el mercado ha generado una notoria diversidad de medios audiovisuales pero este elemento cuantitativo no ha sido sinónimo de calidad en los contenidos, ni menos aún de adecuación a los mandatos constitucionales de respeto al pluralismo informativo y los derechos fundamentales y bienes jurídicos protegidos. El espectáculo de parcialidad y subordinación al poder político de turno ofrecido por los programas informativos de algunas televisiones autonómicas, así como la zafiedad protagonizada por algunos de sus programas de entretenimiento constituyen un ejemplo a rechazar para el modelo de revisión autonómica.

Al igual que en el caso de los medios audiovisuales estatales, en el caso de algunos de ámbito autonómico con una población más numerosa, la necesidad de una autoridad reguladora entiendo que también podría resultar funcional a los efectos de hacer tangibles los principios y mandatos que derivan de la legislación europea, estatal y de la propia Comunidad Autónoma, sobre la regulación del medio audiovisual.

Más allá de las expectativas que en su momento ofrecieron la experiencia de las autoridades audiovisuales autonómicas (en Cataluña, y Andalucía, actualmente en horas bajas y en Navarra, ya suprimido por mor de los efectos de la crisis) es lo cierto que con alguna que otra excepción y según las épocas, la regla general que ofrece la actividad de los medios audiovisuales, tanto públicos como privados, es la de un notorio desapego, tanto del pluralismo como de otros valores constitucionales. Por no mencionar, la distancia con la que tradicionalmente han 
sido tratadas las directrices contenidas en la Directiva europea 89/552/CEE, sobre coordinación de determinadas disposiciones legales y administrativas de los Estados miembros relativas al ejercicio de actividades de radiodifusión televisiva, más conocida como Directiva de la televisión sin fronteras, reformada por la Directiva 2007/65/CE, de 11 de diciembre de 2007 (Directiva de Servicios de Medios Audiovisuales) y de nuevo revisada por la Directiva de 2010. Un desapego que se ha mostrado no solo respecto del pluralismo informativo, sino también en materia de regulación de la publicidad y la específica protección para la infancia y la juventud. Aunque es verdad que en este aspecto quien se lleva la palma del autismo jurídico han sido los operadores de la televisión privada. A modo de ejemplo, ya en octubre de 2004 la prensa escrita denunciaba que Antena 3, Tele5 y TVE1 emitían a diario trece horas de cotilleo y culebrones en horario infantil.

\section{TOMÁS RAMÓN FERNÁNDEZ RODRÍGUEZ}

Mi opinión es radicalmente negativa. Hay, desde luego, un indiscutible componente de servicio público, pero eso no justifica en absoluto que las televisiones autonómicas sigan funcionando indefinidamente como máquinas de perder dinero.

\section{ENRIQUE LINDE PANIAGUA}

La distribución de competencias entre el Estado y las Comunidades Autónomas deriva de la interpretación que ha hecho el Tribunal Constitucional de los apartados 21 y 27 del artículo 149.1 de la Constitución, de manera que se han descentralizado las competencias audiovisuales y se ha centralizado la competencia en materia de telecomunicaciones, es decir, en lo relativo a la concesión de las frecuencias radioeléctricas que ocupan las radios y televisiones. En un Estado descentralizado dicha distribución puede entenderse correcta. El parámetro fundamental a los efectos de la distribución de competencias es el ámbito territorial, de manera que las Comunidades Autónomas tienen la competencia de supervisión en sus respectivos ámbitos territoriales. Pero, a partir de la televisión por satélite el límite territorial se ha desvanecido, porque las televisiones autonómicas pueden emitir por vía satélite, y en esa medida traspasar sus fronteras territoriales. Y en todo caso, la competencia de las Comunidades Autónomas está vinculada a la concesión de las frecuencias correspondientes por el Estado. Se han planteado algunos conflictos ante el Tribunal Constitucional como consecuencia de la colisión de competencias del Estado y las Comunidades Autónomas resultado de las competencias del Estado derivadas de su competencia exclusiva en materia de telecomunicaciones, que han confirmado la competencia exclusiva del Estado en esta materia. 
De gran interés es el contenido de la competencia que se transfiere. Lo cierto es que los márgenes de decisión que tienen las Comunidades Autónomas, plasmadas en su legislación, son considerables en lo organizativo (la forma de los organismos de radiotelevisión pública), los sistemas de control del cumplimiento de los fines de dichas radiotelevisiones, en particular la creación de consejos de redacción, o la creación de consejos audiovisuales. Sin embargo, la legislación del Estado impedía hasta la reforma de 2012 la privatización de las radiotelevisiones públicas autonómicas o la externalización de sus servicios informativos. Es bien conocida la sentencia del Tribunal Constitucional que declaró nula la externalización de los servicios informativos de la radiotelevisión valenciana, una muestra más de corrupción. Pero las reformas legislativas de 2012 permiten la privatización de las televisiones públicas autonómicas, o la externalización de sus servicios informativos. De nuevo hemos asistido a un retroceso considerable en lo relativo a la preservación del pluralismo.

La descentralización de competencias en el Estado autonómico no es objetable. Pero no puede decirse lo mismo del ejercicio por las Comunidades Autónomas de sus competencias en lo relativo a la concesión de licencias tanto de radio (frecuencia modulada) como de televisión en el ámbito autonómico. La arbitrariedad ha sido la norma en esta materia. Los gobiernos de diferentes signos han adjudicado las licencias a sus amigos, con el único objetivo de que la información que suministraran dichas nuevas cadenas les fuera favorable. El balance es lamentable. En muchos casos se han producido impugnaciones a dichas adjudicaciones y en la mayoría de los casos las adjudicaciones han sido anuladas.

¿Se puede evitar lo sucedido? Se puede, pero no solo por la vía de la ley de contratos del sector público, que es correcta en líneas generales, sino con una persecución más eficaz del delito de prevaricación que suele concurrir en dichas adjudicaciones. De nuevo volvemos a lo mismo. Sin un alto nivel ético de los gobernantes, exigida por ciudadanos con un alto nivel ético, ninguna ley será suficiente para evitar la arbitrariedad de los poderes públicos.

\section{MARÍA SALVADOR MARTÍNEZ}

La distribución de competencias en materia de medios tiene cierta complejidad, debido a que es distinta según el medio de que se trate, la modalidad técnica y otros aspectos, pero lo cierto es que no ha dado lugar a conflictos competenciales relevantes. Por otro lado, se trata de una distribución muy similar a la de otros países de nuestro entorno de estructura federal o cuasifederal.

De acuerdo con la Constitución, a los órganos centrales del Estado les corresponde la competencia exclusiva sobre «las normas básicas del régimen de prensa, radio y televisión y, en general, de todos los medios de comunicación social, sin perjuicio de las facultades que en su desarrollo y ejecución correspondan a las Comunidades Autónomas» (art. 149.1.27. ${ }^{\circ}$ ). En desarrollo de esas normas bási- 
cas, a las Comunidades Autónomas les corresponden numerosas competencias legislativas y ejecutivas, entre las que destacan claramente dos. La primera, la competencia para crear y organizar una televisión pública, que derivó, salvo en dos casos concretos, de la previsión contenida en la Ley del Tercer Canal, de 1983, según la cual las Comunidades Autónomas podían gestionar un tercer canal de televisión de titularidad estatal para su ámbito territorial, respetando los principios de actuación y el modelo organizativo establecido para la televisión pública central, puesto que la ley que regulaba dicha televisión tenía carácter básico. En segundo lugar, en relación a radios y televisiones privadas, a las Comunidades Autónomas les corresponde regular y controlar la actividad de los medios privados que emiten en su ámbito territorial, conceder determinado tipo de concesiones y autorizaciones, y sancionar las conductas contrarias a la ley.

En cuanto al ejercicio que se ha hecho de estas competencias, el resultado ha sido asimétrico y heterogéneo, como lo es, por definición, nuestra forma de organización territorial. Así, en relación a la competencia autonómica para crear una televisión pública, Cataluña y el País Vasco asumieron y ejercieron dicha competencia antes aún de que se aprobase la Ley del Tercer Canal (no utilizaron la posibilidad que abrió esta ley porque ya habían asumido esta competencia en su Estatuto de Autonomía); algunas Comunidades no han ejercicio esta competencia nunca, como Cantabria, Navarra o La Rioja; durante unos años Extremadura, en lugar de crear su propia televisión pública autonómica, pactó con Andalucía que la televisión pública andaluza emitiese también en su territorio; en la Comunidad Valenciana la televisión pública ha emitido a lo largo de muchos años, pero ha sido cerrada recientemente «por motivos económicos»; Castilla León no ha creado nunca una televisión pública autonómica, pero, aprovechando las posibilidades que han abierto las últimas reformas legislativas en la normativa básica del sector, hace poco ha concedió a una empresa privada la gestión del canal de la televisión pública autonómica. En cuanto a las competencias de regulación y control de radios y televisiones privadas, en unas Comunidades el gobierno autonómico es quien ejerce directamente estas competencias, mientras que en otras se han creado para ello Consejos audiovisuales, entre los cuales pueden observarse también importantes diferencias respecto a las funciones que asumen y al grado de independencia del poder político del que gozan.

Las diferencias señaladas podrían ser muchas más y referirse a otros muchos aspectos. El problema no es que existan diferencias, algunas de las cuáles son lógicas en un Estado territorialmente organizado como el nuestro. El problema, a mi juicio, radica en las diferencias que revelan que no tenemos una dogmática que explique cuál es la función constitucional de los medios de comunicación en nuestro sistema democrático y cuáles son los mandatos que vinculan al legislador de los medios, ya sea central o autonómico, una dogmática que determine que las principales decisiones de organización, que son las que sirven a la garantía de la libre formación de la opinión pública, no sean diferentes en cada Comunidad Autónoma, como lo son ahora, por ejemplo, para cada una de las radiotelevisiones públicas. 


\section{IGNACIO VILLAVERDE MENÉNDEZ}

A mi juicio no plantean problemas distintos a los que suscita el complejo sistema de distribución competencial acudiendo a la técnica de la legislación básica. Cuestión que en el caso de los medios de comunicación se complica aún más al tratarse de o el desarrollo de la libertad de información o de la regulación de su ejercicio, por lo que deberá estarse a la reserva de ley orgánica para el primer caso, y a lo dispuesto en el difícil artículo 149.1.1 CE.

Un ejemplo claro de esta complejidad es la regulación que hace la Ley 7/2010, de 31 de marzo, General de la Comunicación Audiovisual en su artículo 22 de la competencia, que parece concurrente impropia, sobre concesión de licencias audiovisuales. La norma recurre a la técnica de la coordinación Estado-CCAA, sustentada probablemente en la fe inocente en los mecanismos del federalismo cooperativo, que en el caso español no han dado los frutos esperados.

En mi opinión es una cuestión innecesaria convertir a los medios en materia competencial. La acción estatal en este extremo se ha limitado al sector audiovisual y de las telecomunicaciones, en el que las CCAA han adoptado poco más que el papel de administraciones ejecutoras de la legislación estatal. Basta con el juego sistemático entre la reserva de ley orgánica del artículo $81.1 \mathrm{CE}$, la de ley para la regulación del ejercicio de los derechos fundamentales, donde a las CCAA les corresponde en el ámbito de sus competencias propias efectuar esa regulación, y del artículo 149.1.1 CE, para regular el papel del Estado y las CCAA en este ámbito.

4. ¿Entiende que lo dispuesto en el art. 20.3 CE acerca de que la ley regulará la organización y el control parlamentario de los medios de comunicación social públicos y garantizará el acceso a los mismos de los grupos significativos, respetando el pluralismo y las diversas lenguas tiene en nuestra realidad un nivel de cumplimiento adecuado? ¿Sugeriria Vd. que tal precepto constitucional disfrutase de un desarrollo legislativo diferente?

\section{MARC CARRILLO LÓPEZ}

El precedente más inmediato de la Ley 7/2010 que reguló el nonato CEMA fue la Ley 17/2006, de 5 de junio, de la radio y televisión de titularidad estatal que previó la creación de una autoridad audiovisual, a la que se atribuía «la misión de servicio público de radio y televisión por parte de la Corporación de RTVE, para lo que podrá adoptar las recomendaciones o resoluciones que prevea su regulación» (art. 40). Pero lo que parecía ser inminente dejó de serlo y se quedó en una opción más modesta pero no irrelevante, que prescribió la elección parlamentaria del Presidente del Consejo de Administración de la Corporación de Radio y Te- 
levisión Española (RTVE) por mayoría cualificada (art. 17.1 y 11.4), obligando de hecho al Gobierno a pactar con la oposición un candidato de consenso para el órgano gestor de los medios audiovisuales de carácter público, a fin de encontrar un candidato situado más allá de la obediencia al partido proponente y a sus criterios de oportunidad política.

La nueva regulación se entendió como una vía para dotar de un mayor margen de autonomía al Consejo. Sin embargo, la lógica de funcionamiento «parlamentarizado» de este órgano de control, esto es, de reparto de cuotas de representación en su seno, no ha ayudado a hacer efectivo su primigenio objetivo. De hecho, éste se desvaneció poco tiempo después y buena expresión lo fue la modificación operada tan solo dos años después por el Decreto-Ley 15/2012, de modificación del régimen de administración de la Corporación RTVE, por el que se estableció — tanto para el Presidente del Consejo como para los consejeros- que si transcurridas veinticuatro horas desde la primera votación no se alcanzara la mayoría de dos tercios, sería suficiente con la mayoría absoluta para su elección.

Por otra parte, el control ejercido por el Parlamento sobre los medios públicos de comunicación a través de la Comisión Mixta de Control Parlamentario de la Corporación RTVE y sus sociedades durante la presente legislatura, no se ha mostrado tan eficaz como para, como mínimo, atenuar las acusaciones de parcialidad en favor de la mayoría política gobernante y de baja calidad en demasiados casos de los programas de entretenimiento.

En una eventual reforma constitucional este precepto merecería ser reconsiderado en favor de una opción de control distinta. Y ésta podría pasar por el reconocimiento constitucional de las citadas autoridades independientes, a fin de sentar unas bases más favorables para la calidad democrática de los medios públicos pero también privados, así como de dar entidad a la pluralidad lingüística en España también en los medios de ámbito estatal, que no se reduzca a unas horas de desconexión en lengua autonómica. Sobre la cuestión de las autoridades reguladoras se aportarán algunas consideraciones adicionales en la respuesta a la última pregunta de la encuesta.

\section{TOMÁS RAMÓN FERNÁNDEZ RODRÍGUEZ}

Ya he adelantado mi opinión sobre esto al responder al punto 1.

\section{ENRIQUE LINDE PANIAGUA}

Estamos ante uno de los puntos negros de la legislación audiovisual española. Hasta la fecha el precepto no ha tenido regulación normativa sistemática, al margen de algunas normas dispersas, dejándose a las radios y televisiones públicas que organicen como les parezca oportuno el acceso a las mismas de los grupos sociales y 
políticos significativos. La experiencia no puede ser más negativa. De manera que a mi juicio resulta necesario un desarrollo normativo del precepto en el punto señalado. Dicha norma debe precisar qué debemos entender por dichos grupos y establecer pautas que permitan controlar el cumplimiento de dicha obligación.

\section{MARÍA SALVADOR MARTÍNEZ}

Desde que se aprobó la Constitución dos han sido las leyes del parlamento central que se han ocupado de regular la organización y el control parlamentario de los medios públicos; las Comunidades Autónomas, por su parte, han aprobado las correspondientes leyes que han seguido en términos generales lo establecido por el Parlamento central. A mi juicio, no puede decirse que estas leyes hayan asegurado, ni mucho menos, «el acceso a los mismos (a los medios públicos) de los grupos significativos, respetando el pluralismo»; el objetivo de respetar «las diferentes lenguas», sin embargo, sí creo que se ha alcanzado suficientemente, sobre todo por la existencia de televisiones públicas autonómicas que emiten en las lenguas propias de esas Comunidades Autónomas.

Me centraré en el caso de RTVE, la radiotelevisión pública central, porque, aunque no todas las radiotelevisiones públicas se han organizado igual que RTVE, los problemas a los que aludiré son comunes a todas ellas.

Antes de aprobarse la Constitución, la televisión pública era un servicio público centralizado, dirigido y controlado por el Gobierno, concretamente, por la Dirección General de Radiodifusión y Televisión, que pasaría luego a ser el organismo autónomo Radiotelevisión Española (RTVE). Aprobada la Constitución, en 1980 se redactó la Ley reguladora del Estatuto de Radio y Televisión (ERTV), que transformó a Radiotelevisión Española en un ente público, aunque su estructura organizativa no se modificó sustancialmente, porque el Director General seguía siendo elegido directamente por el Gobierno. La dependencia del Gobierno era, en este sentido, absoluta, e iba además unida a la falta de otro órgano interno que actuase como auténtico contrapeso del Director General. Existía un Consejo de Administración elegido por el Parlamento, pero sin competencias reales para condicionar o controlar la actuación del Director. El ERTV también desarrolló la previsión constitucional relativa al control parlamentario de la televisión pública, que se había introducido con el objeto de evitar la «gubernamentalización» de las televisiones, objetivo que, sin embargo, y por las razones que ya conocemos, no se consiguió. En todo caso, la «parlamentarización» de las televisiones públicas, a mi juicio, no es el mejor modo de garantizar la independencia del poder político, la lucha política y los partidos políticos: primero, porque, en un sistema parlamentario como el nuestro, el signo político de la mayoría parlamentaria es el mismo que el del Gobierno; y, segundo, porque el parlamento es un órgano tan «político» como el Gobierno.

La situación de RTVE de dependencia absoluta del Gobierno, claramente incompatible con el respecto al pluralismo y con la función que una televisión 
pública debe cumplir, se mantuvo desde 1980 hasta 2006, año en que el ERTV fue sustituido por la Ley de RTVE. La nueva ley pretendía garantizar la independencia de la radiotelevisión respecto del Gobierno reforzando su dependencia del Parlamento, para lo cual disponía que el órgano central decisorio de RTVE pasase a ser el Consejo de Administración, cuyos miembros serían elegidos por el Congreso y el Senado mediante una mayoría cualificada de dos tercios. En la práctica, como sucede en todos los nombramientos de este tipo, el Parlamento aplica el conocido «sistema de cuotas» de modo que los nombramientos se reparten entre los grupos políticos (partidos políticos) en proporción a su representación parlamentaria; por ello, en el Consejo de Administración de RTVE se refleja la relación de fuerzas del Parlamento y se reproduce la lucha política entre ellas. En 2012 se ha modificado parcialmente este sistema de elección para establecer que, en caso de que no se alcance la mayoría exigida (dos tercios), en un plazo de veinticuatro horas será suficiente la mayoría absoluta para elegir a los miembros del Consejo. Este mismo sistema se aplica para elegir al Presidente, que tiene voto dirimente en el Consejo en caso de empate, y que es elegido por mayoría de dos tercios en el Congreso o por mayoría absoluta veinticuatro horas después. Es decir, un partido político con mayoría absoluta en el parlamento podría elegir a todos los miembros del Consejo y al Presidente de RTVE.

La Ley de RTVE de 2006 supuso un importante avance, pero queda camino por recorrer para que podamos decir que nuestra televisión pública está suficientemente alejada de la lucha política y puede cumplir la función de garantizar la libre formación de la opinión pública. Para ello haría falta mejorar las normas de organización y procedimiento de las televisiones públicas e incorporar todas las medidas que puedan asegurar la independencia funcional, orgánica, personal y financiera de estas instituciones. Y, aun así, eso no sería suficiente. Las normas llegan hasta donde pueden llegar. Recayendo la mayoría de los nombramientos en el Parlamento o el Gobierno, siempre será posible que los partidos nombren a personas de confianza y que influyan en ellas cuando lo consideren necesario para sus intereses. Frente a esto no hay más solución que cultura política y el convencimiento por parte de todos de que la televisión pública no puede utilizarse con fines partidistas. Lamentablemente, después de tantos años de control directo de la televisión pública por parte del Gobierno, nuestra cultura política en este terreno es muy escasa.

Finalmente, en cuanto al acceso a la televisión pública por parte de los «grupos sociales significativos» al que alude el art. 20.3 CE, el Tribunal Constitucional ha reconocido la existencia de un derecho de acceso, pero cuya configuración queda en manos del legislador; éste se ha limitado a establecer que RTVE asegurará en su programación la expresión de la pluralidad social, ideológica, política y cultural de la sociedad española, y reservará para ello espacios específicos. El problema es que estamos una declaración de principios que no ha ido acompañada de las normas de organización y procedimiento que podrían hacer realidad esa expresión de pluralismo social. 


\section{IGNACIO VILLAVERDE MENÉNDEZ}

El desarrollo de este precepto está ignoto en el sistema constitucional español. En ninguna de las normas reguladoras de los medios de comunicación en España se prevé un sistema efectivo y real de acceso de los grupos significativos, ni se establece un verdadero control parlamentario de este tipo de medios. La participación de las Cortes Generales o de los parlamentos autonómicos se limita al control sobre el nombramiento de la dirección del medio de comunicación o a su designación en el mejor de los casos. Pero no se fijan mecanismos jurídicos que impongan ni un control ni un acceso reales.

El artículo 41.2 de La Ley 7/2010, de 31 de marzo, General de la Comunicación Audiovisual no ha abordado esta cuestión de la manera a mi entender más adecuada. Atribuye a los parlamentos y a las autoridades audiovisuales, donde las haya, el control de los medios públicos y el cumplimiento de su función de servicio público. En este extremo la norma pone especial énfasis en el papel que desempeñarían las autoridades audiovisuales en el control sobre el cumplimiento de su función como servicios públicos (artículo 41.3).

Cierto que algo se ha avanzado en relación con el nombramiento de los órganos de gobierno de los medios de comunicación públicos, en la medida en que el artículo 11 (y el artículo 17) de la Ley 17/2006, de 5 de junio, de la radio y la televisión de titularidad estatal prevé para el caso de la RTVE que su consejo de administración y su presidente son elegidos y designados por las Cortes Generales; aunque el Director del ente sigue siendo nombrado por el Gobierno. El control parlamentario que prevé su artículo 39 apenas excede de la mera remisión de memorias e informes sobre la ejecución del contrato-programa y el mandato-marco; o el derecho de acceso al que le dedica un único precepto, artículo 28, programático y vacío de contenido. No es muy distinta la regulación de las CCAA de sus leyes sobre sus propios medios (televisiones de ámbito autonómico).

No obstante, ninguna de estas normas acierta a establecer un sistema efectivo de control, apenas limitado a las comparecencias de sus presidentes y directores, y que no parece que satisfaga la dación de cuentas que sería esperable en un medio público.

5. Más en concreto ¿desea hacer alguna glosa sobre el régimen legal de concesión de televisiones privadas?

\section{MARC CARRILLO LÓPEZ}

La utilización privativa del espacio radioeléctrico para la prestación de servicios audiovisuales ha de partir de un hecho incontestable: se trata de un bien es- 
caso y cuyo acceso atribuye al concesionario una gran capacidad de incidencia en la sociedad de la información. Es decir, un notable poder de influencia. A este respecto, parece evidente que la legislación sectorial habría de evitar la atribución a las autoridades competentes, como advierte DoméneCH PASCUAL ${ }^{1}$, de plena discrecionalidad para la concesión de licencias a quien consideren más conveniente. Porque es evidente que el interés político no siempre coincide con el interés general.

Lo ocurrido tanto a nivel estatal como en el ámbito autonómico de favoritismo en beneficio de empresas complacientes con la mayoría política gobernante, constituye hoy ya una lacra en el panorama audiovisual español. Los principios constitucionales y derechos constitucionales de objetividad (art. 103.1 CE), eficiencia (art. 31.2 CE), no discriminación (art. 14 CE), derecho a la información (art. 20.1.d) y libre competencia (art. $38 \mathrm{CE}$ ) no siempre son el fundamento justificativo de la concesión de licencias. Ello ha conducido a considerar que el actual sistema de asignación y reasignación de licencias, presenta problemas que exigen cambios normativos así como también de determinadas prácticas administrativas. Entre los elementos de crítica que han sido subrayados destacan: la indeterminación legal de los criterios de adjudicación; la indeterminación de los criterios establecidos en las bases de los concursos produce arbitrariedad, corrupción y litigiosidad; el procedimiento de gestión administrativa resulta costoso; su regulación muestra incoherencias con la regulación de los contratos del sector público; la adjudicación simultánea de licencias favorece la homogeneidad y la continuidad, etc. ${ }^{2}$.

\section{TOMÁS RAMÓN FERNÁNDEZ RODRÍGUEZ}

El sistema previsto en el artículo 27 de la Ley General de Comunicación Audiovisual de 31 de Marzo de 2010 no me parece mal, pero carezco de experiencia directa sobre su funcionamiento.

\section{ENRIQUE LINDE PANIAGUA}

La legislación que regula las televisiones privadas ha sufrido una evolución espectacular desde la Ley de Televisión Privada de 1988. Puede decirse que dicha evolución ha realizado un recorrido contrario a los principios de pluralidad interna y pluralidad externa de los mismos. Se trata a mi juicio de una de las más graves involuciones que ha sufrido nuestro sistema democrático.

1 Doménech Pascual Gabriel, G., «La adjudicación de las licencias en el mercado audiovisual». En: A. Boix Palop y J.M. . Vidal Bertrán (coord.), La nueva regulación del audiovisual: medios, derechos y libertades, Thomson Reuters/Aranzadi, Navarra, 2014, pp. 99-120.

2 Ibidem, p. 100 y ss. 
Desde la primera legislación sobre televisión privada en que se concibió un sistema para preservar el pluralismo externo e interno en las mismas se ha producido una deriva continuada contraria al pluralismo. En efecto, en 1988 el número de socios mínimo era de 4, con participaciones máximas del $25 \%$ del capital y, además, ningún socio capitalista podía serlo de más de una televisión. Desde 1988 los respectivos gobiernos irán desmantelando poco a poco dicho sistema hasta la situación actual en que las empresas audiovisuales pueden tener un único socio y, además, se permite la posibilidad de que una misma persona física o jurídica pueda ser socio de varias empresas audiovisuales. De este modo hemos llegado a la situación actual en que el mercado televisivo estatal está en manos de dos empresas que controlan cerca del $80 \%$ de la audiencia y del mercado publicitario.

El proceso de concentración de medios audiovisuales fue facilitado por el Gobierno de Rodríguez Zapatero con la finalidad de permitir la fusión de las nuevas cadenas Sexta y Cuatro con Antena 3 y Telecinco. Sin duda la Sexta y la Cuatro, en la órbita del Gobierno socialista, habían fracasado estrepitosamente, de manera que se hacía un favor extraordinario a dichas cadenas y además se conseguía eliminarlas de la competencia de las privadas "primigenias». Los procesos de concentración de medios de comunicación es una de las enfermedades más extendidas en occidente y el mayor de los peligros para la democracia.

La televisión pública estatal ha perdido su posición hegemónica como resultado de su exclusión del mercado publicitario, debido al Gobierno de Rodríguez Zapatero. Si la televisión pública dejaba de ser un instrumento al servicio del Gobierno, Rodríguez Zapatero y su gobierno debieron pensar que no merecía la pena conservarla. Todo menos pensar que la televisión pública podía ser un instrumento para la información veraz de los ciudadanos.

Contestando de modo más directo la pregunta creo que la implicación tan significativa de los medios de comunicación en las sociedades democráticas exigiría la exclusividad de la actividad y la incomunicación entre medios de comunicación. Esto es, las empresas dedicadas a la información no debieran pertenecer o estar participadas por otras empresas fuera cual fuera su naturaleza y objeto. Y los propietarios de los medios no debieran serlo de más de un medio de comunicación. Una utopía que difícilmente se cumplirá, pero que sería imprescindible para garantizar la independencia de los medios de los poderes públicos y privados.

Los sucesivos Gobiernos del PSOE y del PP nunca se situaron en la posición imparcial en relación con los medios de comunicación que debiera exigírseles. Todos ellos han practicado una política sectaria utilizando el instrumento de la Ley. Por suerte para los respectivos gobiernos todavía no existe la prevaricación legislativa y, de otra parte, los mecanismos de control de constitucionalidad no funcionaron nunca en relación con los medios de comunicación. 


\section{MARÍA SALVADOR MARTÍNEZ}

Una vez que el sector de la televisión se abrió a las empresas privadas surgió la necesidad de regular la actividad de los nuevos emisores privados y desempeñar dos tareas fundamentales para el correcto funcionamiento de ese nuevo mercado: otorgar las correspondientes licencias, autorizaciones o concesiones, y controlar el cumplimiento por parte de las televisiones privadas de las normas de programación y de las normas anticoncentración que se establecieran para ellas. Si la competencia para llevar a cabo ambas tareas se atribuye al Gobierno, se está dejando en manos de éste (es decir, del partido político con mayoría parlamentaria) la posibilidad de influir de manera determinante en la actuación de las televisiones privadas y, con ello, de condicionar el proceso de libre formación de la opinión pública. Esa posibilidad se incrementa o disminuye según cuál sea el grado de discrecionalidad que las normas permitan al Gobierno en el ejercicio de dichas tareas -especialmente del otorgamiento de concesiones-, grado de discrecionalidad que está directamente en relación con lo reglado, previsto, detallado y transparente que sea el procedimiento a través del cual tiene que actuar el Gobierno.

En este sentido, me temo que el régimen jurídico de nuestras televisiones privadas es manifiestamente mejorable. En primer lugar, con carácter general es el Gobierno, tanto central como autonómico, el responsable de decidir la convocatoria de concurso para la adjudicación de concesiones de canales de televisión a empresas privadas y de resolver dicho concurso. En numerosos países de nuestro entorno esta competencia corresponde a un «consejo audiovisual» independiente del Gobierno (sobre el grado de independencia de estos consejos me remito a lo dicho en preguntas anteriores en relación a la independencia de los organismos públicos de radiotelevisión). La mayoría de dichos consejos audiovisuales fueron creados como órganos asesores del Gobierno, con competencias limitadas, pero posteriormente se les fueron atribuyendo nuevas facultades (potestad normativa, sancionadora, facultad de otorgar las licencias o autorizaciones, competencias de supervisión y control...), hasta convertirse en los organismos responsables del sector de la televisión privada. En nuestro país la gestación de un Consejo audiovisual de ese tipo ha durado más de dos décadas sin que ésta haya llegado a buen término. Desde 1993, año en que se constituyó en el Senado la conocida Comisión sobre Contenidos Televisivos presidida por Victoria Camps, se estuvo reclamando la creación de un Consejo audiovisual. Éste finalmente fue previsto por la Ley General de Comunicación Audiovisual de 2010, en la que se le asignaban, entre otras, facultades en relación al procedimiento de otorgamiento de concesiones. Sin embargo, este Consejo nunca llegó a constituirse. Con la creación de la «ambiciosa» Comisión Nacional de los Mercados y la Competencia (CNMC), las funciones que se habían previsto para el Consejo Audiovisual se repartieron entre el Gobierno y la CNMC, a la que no ha correspondido ninguna facultad en relación a los concursos de concesiones; todas han quedado en manos del Gobierno. 
En el ámbito de la Comunidades Autónomas sí se han creado Consejos audiovisuales, entre los que destaca el Consejo creado en Cataluña por haber sido el primero de ellos y por su amplio ámbito de competencias, pero el conjunto de los Consejos que se han creado en las Comunidades Autónomas, como ya se dijo antes, resulta muy asimétrico y heterogéneo.

En segundo lugar, en cuanto al grado de discrecionalidad que las normas permiten al Gobierno, sin entrar en detalles concretos, sería recomendable tratar de limitar en la mayor medida de lo posible dicha discrecionalidad y para ello, nuevamente, se podría acudir a la normativa y la experiencia de otros países de nuestro entorno.

\section{IGNACIO VILLAVERDE MENÉNDEZ}

No soy un experto en esta materia, pero hasta donde se me alcanza, a pesar de los cambios introducidos en el sistema desde los años noventa, creo que siguen manteniéndose los mismos inconvenientes constitucionales que tuvo el sistema de concesión administrativa de la Ley del 88. La Ley 7/2010, de 31 de marzo, General de la Comunicación Audiovisual mantiene la declaración de servicio público de la comunicación audiovisual, eufemísticamente denominado «de interés general» (un «servicio público» blando), lo que permite al Estado mantener su control sobre la creación de medios audiovisuales, exigiendo la comunicación previa en el caso de los electrónicos y conservando la técnica de la licencia previa en los hertzianos. Si la CE garantiza el derecho a difundir ideas, opiniones, pensamientos e información por cualquier medio de difusión, como ya apuntara BASTIDA, el sistema de acceso a los canales y frecuencias no puede seguir sometido a un régimen de autorización previa a modo de remedo de «prohibición con reserva de autorización» con la excusa de la escasez de espacio y frecuencia que justificaba el sistema anterior de concesión. Tampoco parece justificado a esta altura de los tiempos que se mantenga esa calificación de servicio público blanco (de «interés general») con el que se pretende sortear la Directiva de liberación de servicios y justificar el sistema de licencias para las hertzianas.

Por otro lado, este sistema de control en el input del proceso de comunicación pública ha tenido dos consecuencias significativas: de un lado, el Estado ha cejado en toda ocasión de someter a los canales privados (y también a los públicos) a un efectivo control en su output (contenidos y formas informativos) dirigido a preservar los derechos del público y especialmente de los grupos más vulnerables, porque su empeño se ha puesto en el control de quién puede crear una empresa audiovisual. De hecho, la Ley creó un Consejo Estatal de Medios Audiovisuales cuya existencia fue truncada tempranamente porque sus funciones fueron atribuidas a la Comisión Nacional de los Mercados y la Competencia por la Ley 3/2013, de 4 de junio. Ese ente hubiera podido colmar razonablemente las expectativas de un 
control efectivo del cumplimiento de las exigencias de la ley sobre todo en relación con los contenidos audiovisuales.

Resulta paradójico que el acceso al mercado audiovisual radiotelevisivo esté controlado por el Estado (sin justificación ni técnica ni constitucional), y sin embargo ese mercado se diseña para que su efectivo funcionamiento sea completamente desregulado. Por otro lado, y a consecuencia de este diseño desafortunado del mercado audiovisual radiotelevisivo, y dada la competencia de internet y los productos audiovisuales que se ofrecen a través de la red, el mercado radiotelevisivo tradicional ha tendido a un proceso de concentración intensa, hasta el punto de que hoy prácticamente es un mercado controlado por dos únicos grupos audiovisuales (Mediaset y Atresmedia Corporación).

No parece que en esto el modelo haya intensificado el pluralismo informativo externo. El interno sigue siendo otra asignatura pendiente en nuestro sistema constitucional.

6. ¿Cómo valora el nivel de independencia de la prensa, radio y televisión privada de nuestro país tras la incidencia en la misma de la crisis económica? ¿Ve viable que desde el ordenamiento jurídico se puedan aportar terapias al respecto o entiende preferible la neutralidad del legislador?

\section{MARC CARRILLO LÓPEZ}

La crisis económica ha supuesto una minusvaloración de los derechos fundamentales por el mismo legislador, que se ha traducido en disposiciones que ya resultan emblemáticas de esta lógica regresiva: la reforma de la legislación laboral, la nueva legislación sobre protección de la seguridad ciudadana, la nueva legislación penal, etc.

Por su parte, los medios de comunicación no han necesitado de la acción restrictiva del legislador para ver limitada su función de «perro guardián del poder»: la crisis económica ha facilitado su adocenamiento. Pero además los problemas de financiación, la necesidad de reconvertirse ante el impacto de la prensa digital, el bajo nivel de consumo de prensa diaria por la ciudadanía, constituyen problemas de naturaleza estructural que han agravado su situación de dependencia. Por otra parte, la imperiosa necesidad de preservar la sostenibilidad financiera de la mayoría de medios, ha coadyuvado a la entrada en sus órganos de dirección de entidades financieras que, sin ningún género de duda, ha incidido en su línea editorial y, por tanto, en su independencia.

¿Qué puede hacer el legislador? Poco ante los déficits estructurales expuestos. Por el contrario, alguna posibilidad le queda para paliar los demoledores efectos que sobre el papel de los medios en la sociedad democrática tiene su de- 
pendencia del poder económico y financiero y las malas prácticas informativas $Y$ no es otra que preservar que la información y, en general, la programación difundida se atenga a los principios básicos del ordenamiento jurídico. La fórmula ya evocada en el ámbito de los medios audiovisuales de una autoridad reguladora, merecería ser explorada.

La naturaleza jurídica de estos entes reguladores de la comunicación audiovisual se caracteriza porque son creados por ley como administraciones singulares, dotadas de autonomía orgánica y funcional, que actúan de manera independiente de los poderes del Estado, ejerciendo sus funciones en relación con las que dispone el Gobierno sobre el mismo sector de acuerdo con el principio de competencia. Desde un punto de vista material, sus competencias se proyectan sobre la regulación de las condiciones que han de regir la actividad de los medios de comunicación, sin excluir también un cierto nivel de intervención sobre los contenidos. En todo caso, es una regla general que sus decisiones, incluida la potestad reglamentaria a través de las Instrucciones que aprueban para la regulación del sector, están sometidas al control judicial.

A este respecto es preciso subrayar que, en el marco de una sociedad democrática, regular el medio audiovisual no es sinónimo de censura o control previo de contenidos. Más bien, todo lo contrario, de lo que se trata es de asegurar la garantía de los derechos fundamentales que entran en juego, entre ellos el de comunicar y recibir información aunque su contenido, por ejemplo, suscite inquietud en las más altas instancias del Estado o de las corporaciones privadas. Y también, y con el mismo grado de intensidad jurídica, salvaguardar los derechos de la personalidad ante comunicaciones de contenido lesivo. En ambos casos, son los derechos del público destinatario lo que están en juego. Por ello, es preciso evitar que los productos que ofrezcan los medios audiovisuales públicos y privados, ya sean para informar, formar o entretener, devengan un mero objeto de mercadeo a la búsqueda de la audiencia, con absoluta abstracción del respeto que merecen derechos e intereses constitucionalmente protegidos. En este sentido, cuando desde determinados sectores se llega a decir que la creación de los órganos reguladores como autoridades administrativas independientes, es un acto de tutela pública de la libre expresión o que no se pueden poner puertas a la libertad de comunicación, visto el panorama que ofrecen algunos contenidos radiofónicos y televisivos, no es irrazonable pensar que lo único que de verdad pretenden es mantener una cuota de negocio con independencia cuando no menosprecio de cualquier mandato constitucional.

\section{TOMÁS RAMÓN FERNÁNDEZ RODRÍGUEZ}

Los medios escritos hacen lo que pueden para sobrevivir y para encontrar un lugar en un escenario sociológico de cambio. No soy partidario de que el legislador intervenga en ningún sentido, al menos por el momento. 
Como usuario no tengo reproches que hacer a la independencia de la radio y televisión privada. No tengo costumbre de oír la radio y simplemente no conecto las emisoras de televisión que no me agradan.

\section{ENRIQUE LINDE PANIAGUA}

La respuesta de las televisiones privadas, probablemente por supuestas deudas pendientes con el Gobierno, o respondiendo a una estrategia que tiene como único objetivo conseguir una gran cuota de audiencia, ha sido la de establecer cuatro líneas de trabajo: por una parte llevar al primer plano los casos de corrupción; por otra utilizar las cadenas secundarias (Cuatro y Sexta) para la promoción de los partidos políticos minoritarios, Podemos y Ciudadanos, son tratados, antes y después de las elecciones europeas, como si representaran a la inmensa mayoría de los españoles; en tercer lugar convertir los telediarios en programas de sucesos y sucesos luctuosos; y en cuarto lugar dedicar al futbol y los programas frívolos gran parte de la programación. Estas líneas de programación no son nuevas pero desde el comienzo de la crisis se han consolidado.

La información veraz como ejercicio reflexivo, que hubiera sido fundamental para situar de un modo panorámico a los ciudadanos ante la crisis, ha estado ausente en la programación de las televisiones privadas. La reflexión no tiene espacio en los formatos televisivos que exigen, cada vez más, lo que se llama en la jerga televisiva «un completo», es decir, manifestaciones en breves segundos, porque de otro modo se considera que el telespectador cambiará de cadena. Por otra parte, las tertulias, tanto en las radios como en las televisiones, se caracterizan por estar pobladas, salvo excepciones, por opinadores que muy poco o nada saben de lo que opinan, de manera que poco contribuyen a facilitar el conocimiento de lo que está sucediendo a los ciudadanos.

Por lo que se refiere a la prensa la crisis económico financiera ha coincidido con un descenso espectacular de ventas, en un país como el nuestro caracterizado por el pobre porcentaje de lectores de prensa, uno de los más bajos de occidente. No es lugar este para analizar la crisis de la prensa, pero alguna porción de responsabilidad debe haber tenido el marcado sectarismo de la misma. No obstante, algunos diarios proporcionan una información valiosa y opiniones de expertos relevantes tanto españoles como extranjeros. Pero todo parece indicar que solo una minoría de españoles lee con detenimiento no ya varios periódicos sino un periódico al día. La influencia de los diarios parece haberse reducido, fundamentalmente, a la clase política y a las cúpulas empresariales.

Los medios de comunicación privados no son independientes ni de los poderes públicos ni de los poderes privados y resulta evidente que, por si mismos, lejos de dirigirse en la dirección de la independencia han hecho todo lo contrario. Ahora bien, ¿significa lo anterior que los poderes públicos deben intervenir mediante leyes u otros instrumentos para preservar la independencia? El remedio, 
como dice el refrán español, puede ser peor que la enfermedad. Antes he apuntado algunas medidas que podríamos denominar estructurales; exclusividad, incomunicación, etc. En mi opinión, acaso, la legislación debiera adoptar medidas estructurales, sin entrar bajo ningún concepto en los contenidos de la información o la opinión. Pero lo cierto es que han fracasado quienes han intentado frenar la concentración de empresas de comunicación, han pretendido potenciar el pluralismo interno y externo de los medios, o la exclusividad del objeto de las empresas de comunicación.

\section{MARÍA SALVADOR MARTÍNEZ}

La crisis económica, como es lógico, ha agravado todos los problemas que se han ido señalando al responder a las preguntas de esta encuesta. En el sector de los medios privados la crisis, unida a la aparición de nuevos medios y nuevas tecnologías, ha causado verdaderos estragos. La difícil situación económica por la que pasan los medios privados les hace mucho más vulnerables ante cualquier tipo de presión, incluidas las posibles presiones del poder político. Por eso me resulta difícil, y peligroso, pensar en soluciones inmediatas que tengan su origen en los poderes públicos. Probablemente la solución debería plantearse en términos ambiciosos, es decir, el legislador tendría que apostar por establecer un modelo en el que se definiese la función que corresponde a los medios públicos y privados, y tanto a unos como a otros se les dotase de la organización y el régimen jurídico necesarios para cumplir dicha función. Sin una reforma de este calado, cualesquiera otras medidas resultarían meros parches.

\section{IGNACIO VILLAVERDE MENÉNDEZ}

No poseo datos que me permitan pronunciarme con conocimiento sobre dicho extremo. Mi impresión es que los medios de comunicación tradicionales poseen un cierto sesgo ideológico (línea editorial) que resulta normal en una sociedad democrática por cuanto no deja de expresar la propia pluralidad ideológica del conjunto de los ciudadanos. Tampoco poseo información fiable sobre la real existencia de manipulaciones, controles o presiones por parte especialmente del medio económico. Es cierto que en España los medios tradicionales son propiedad de un grupo relativamente pequeño de empresas. No hay que olvidar que los medios de comunicación no dejan de ser negocios lucrativos, y su forma jurídica es la de sociedades mercantiles que, lógicamente, persiguen obtener beneficios. Tampoco se olvide que sin obtenerlos no sobrevivirían, siendo su alternativa la existencia de medios públicos o subvencionados por el poder público. No existe mecanismo jurídico eficaz para expulsar del mercado económico de los medios el riesgo de su control y manipulación económica o política. Su único antídoto es la 
protección y fomento de la pluralidad de medios, lo que podría aconsejar una política de incentivos a la creación y sostenimiento de medios de comunicación. (RAllo Lombarte). Pluralismo que desde luego no se logra con las magras previsiones, dos artículos, de la Sección III Capítulo I Título III de la Ley 7/2010, de 31 de marzo, General de la Comunicación Audiovisual.

Sin embargo, la extrema facilidad que supone internet como instrumento para la difusión universal e indiscriminada de noticias y el evidente incremento del sector audiovisual informativo en ese medio ha servido para aumentar exponencialmente las fuentes plurales de información. Pero también ha conllevado el riesgo del autismo informacional de unos ciudadanos que segmentan y definen sus fuentes de información de manera que sólo reciben los mensajes que resultan de su gusto y en su aislamiento no reciben influencia de mensajes de «otros». Está aún por estudiar este fenómeno, su impacto y efectos.

La crisis económica ha polarizado a los medios de comunicación. La tendencia a la concentración de la prensa local y regional, controlada por dos grandes grupos, de las TV privadas, que lo son por otros dos grandes grupos con ramificaciones en la prensa, y la no menor concentración en el sector de las radios, no arroja un panorama alentador para el pluralismo informativo.

Tampoco es muy halagüeño el panorama en el deseable pluralismo interno, que serviría de instrumento para paliar la falta de pluralismo externo. La ausencia de un estatuto general de la profesión periodística, del desarrollo de la cláusula de conciencia (que sigue siendo un Godot constitucional, en palabra de De La Quadra), y de estatutos de redacción, tampoco arrojan un panorama halagüeño.

$$
* * *
$$

\section{TITLE: Academic survey about the Independence of the mass media}

ABSTRACT: In this academic survey a group of Constitutional Law Professors answer some questions about the situation of mass media in a democratic system and specifically about the role of public opinion in a democratic State, the role of the media in the development of the public opinion, the legal framework of the media and the problems that the legislator faces in order to guarantee the freedom and the social pluralism expression in the communication processes.

RESUMEN: En esta encuesta un grupo de profesores de Derecho Constitucional contestan un conjunto de preguntas sobre la independencia de los medios de comunicación, y, especialmente, sobre la necesidad de atender a la libre formación de la opinión pública, el papel que desempeñan los medios en una sociedad democrática, el régimen jurídico que se establece para los medios de comunicación y los problemas a los que se enfrenta el legislador en orden a garantizar la libertad y la expresión del pluralismo social en los procesos de la comunicación.

KEY WORDS: Independence of media, public opinion, democratic system, legal framework of the media.

Palabras Clave: independencia de los medios de comunicación social, opinión pública, sistema democrático, régimen jurídico de los medios de comunicación. 
